\title{
Reactions Between Chalcogen Donors and Dihalogens/Interalogens: Typology of Products and Their Characterization by FT-Raman Spectroscopy
}

\author{
Massimiliano Arca, M. Carla Aragoni, Francesco A. Devillanova, Alessandra Garau, Francesco Isaia, \\ Vito Lippolis, Annalisa Mancini, and Gaetano Verani
}

Dipartimento di Chimica Inorganica ed Analitica, Università degli Studi di Cagliari, S.S. 554 Bivio per Sestu, 09042 Monserrato (CA), Italy

Received 22 June 2006; Revised 4 October 2006; Accepted 5 October 2006

\begin{abstract}
The chemical bond and structural features for the most important classes of solid products obtained by reacting chalcogen donors with dihalogens and interhalogens are reviewed. Particular attention is paid to the information the FT-Raman spectroscopy can confidently give about each structural motif considered in the absence of X-ray structural analyses.
\end{abstract}

Copyright (c) 2006 Massimiliano Arca et al. This is an open access article distributed under the Creative Commons Attribution License, which permits unrestricted use, distribution, and reproduction in any medium, provided the original work is properly cited.

\section{INTRODUCTION}

Reactions of dihalogens $\left(\mathrm{I}_{2}, \mathrm{Br}_{2}\right)$ and interhalogens ( $\left.\mathrm{IBr}, \mathrm{ICl}\right)$ with organic molecules containing group 16-donor atoms (LE; $\mathrm{L}=$ organic framework, $\mathrm{E}=\mathrm{S}, \mathrm{Se}$ ) have received renewed interest in recent years. This is due to two principal reasons: their intrinsic interest and their implications in different fields of research which span from synthetic to biological, material, and industrial chemistry. For example, 1methyl-imidazole-2-thione and related molecules show considerable antithyroid activity in vivo via $\mathrm{I}_{2}$ complexation [ $1-$ $3] ; \mathrm{I}_{2}$ and $\mathrm{IBr}$ adducts of perhydrodiazepine-, and piperazine2,3-dithione derivatives can oxidize gold $(0)$, palladium $(0)$, and platinum $(0)$ [4-6]; a similar activation of metal $(0)$ powders is observed with the $\mathrm{I}_{2}$ adducts of phosphine sulfide compounds [7-9]; complexes between $I_{2}$ and sulfur containing molecules can have interesting electrical properties [10].

These reactions, particularly using chalcogenone donors featuring a $>\mathrm{C}=\mathrm{E}(\mathrm{E}=\mathrm{S}$, Se $)$ double bond can follow a variety of pathways depending on both the acid/base nature of the reactants and the experimental conditions used, the most important one being the formation of neutral charge-transfer (CT) "spoke" adducts featuring almost linear $\mathrm{E}-\mathrm{X}-\mathrm{Y}$ moieties $[\mathrm{X}=\mathrm{Y}=\mathrm{I}, \mathrm{Br}$ or $\mathrm{X}=\mathrm{I}, \mathrm{Y}=\mathrm{Br}, \mathrm{Cl}(\mathrm{E}=\mathrm{S})$; $\mathrm{X}=\mathrm{Y}=\mathrm{I}$ or $\mathrm{X}=\mathrm{I}, \mathrm{Y}=\mathrm{Br}, \mathrm{Cl}(\mathrm{E}=\mathrm{Se})][5,6,11-84]$ or insertion adducts containing "T-shaped" $\mathrm{X}-\mathrm{E}-\mathrm{Y}$ fragments
$[\mathrm{X}=\mathrm{Y}=\mathrm{Br}, \mathrm{Cl}(\mathrm{E}=\mathrm{S}) ; \mathrm{X}=\mathrm{Y}=\mathrm{I}, \mathrm{Br}, \mathrm{Cl}$, or $\mathrm{X}=\mathrm{I}$, $\mathrm{Y}=\mathrm{Br}(\mathrm{E}=\mathrm{Se})$; other $\mathrm{X}-\mathrm{E}-\mathrm{Y}$ hypervalent compounds are obtained by different synthetic strategies, see Devillanova et al in this issue of BC\&A] [59, 65, 66, 69, 71, 85-89]. Other different structural archetypes have also been established by $\mathrm{X}$-ray diffraction analysis for the products of these reactions; they mainly include ionic products such as two-chalcogencoordinated halogen $(\mathrm{I})$ complexes $\left[(\mathrm{LE}-\mathrm{X}-\mathrm{EL})^{+}\right][43,45$, $65,90]$, and dications containing a chalcogen-chalcogen single bond $\left[(\mathrm{LE}-\mathrm{EL})^{2+}\right][3,65,72,91,92]$. Polyhalides of exciting structural complexity can be found as counteranions of these ionic compounds [3, 91, 92]. A significant example is represented by the distribution of products from the reactions of $\mathrm{N}$-methylbenzothiazole-2(3H)-thione (1) and $\mathrm{N}$ methylbenzothiazole-2(3H)-selone (2) with $\mathrm{I}_{2}, \mathrm{Br}_{2}, \mathrm{IBr}$, or ICl (Figure 1).

This variety of products, besides being very puzzling from a kinetic and thermodynamic point of view $[66,77,88$, 89,93 ], represents a serious challenge when it comes to characterize the outcome of the reactions between chalcogendonor ligands and dihalogens and interhalogens, especially when an X-ray crystal structure determination is not possible. The FT-Raman spectroscopy was proved to be of particular help in giving qualitative structural information particularly in the case of compounds from reactions with diiodine [65]. However, a confident correlation between structural features and vibrational properties requires the analysis 

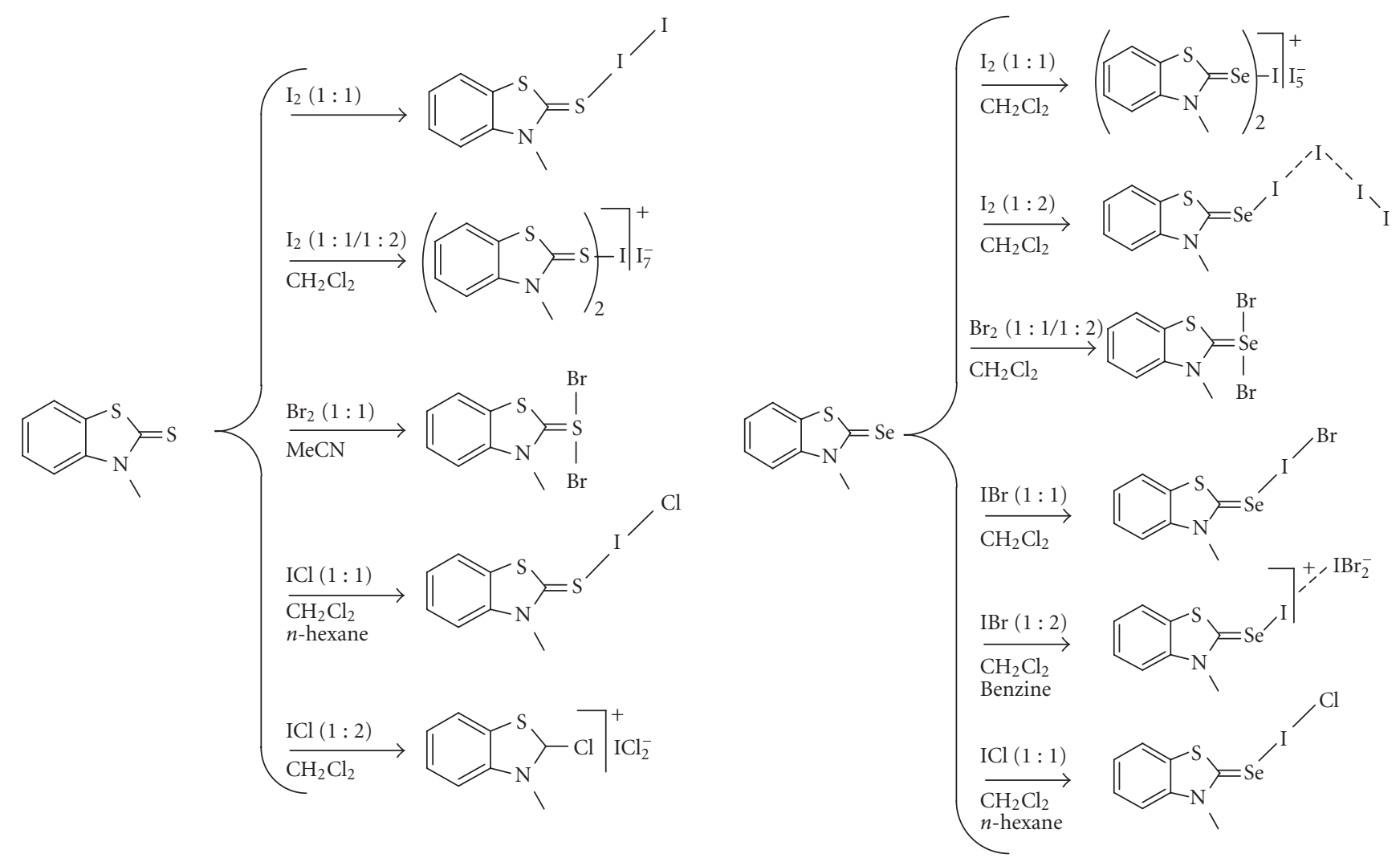

FIGURE 1: Schematic representation of the compounds obtained from the reactions of $N$-methylbenzothiazole-2(3H)-thione $(\mathbf{1})$ and $N$ methylbenzothiazole-2(3H)-selone (2) with $\mathrm{I}_{2}, \mathrm{Br}_{2}, \mathrm{IBr}$, or ICl characterized by X-ray diffraction analysis. This scheme must be intended purely as an illustration of the various compounds with no implications on the nature of the chemical bonds involved.

of a large number of crystallographically characterized compounds for each structural motif available.

Here we will not attempt to give an overview of all of the knowledge on the reactivity of chalcogen-donor molecules towards dihalogens and interhalogens; instead, we will focus our attention exclusively on the chemical bond and structural features, and on the main information the FTRaman spectroscopy can confidently give about each particular structural motif so far characterized for the compounds obtained by reacting chalcogen donors with dihalogens/interhalogens.

\section{DISCUSSION}

\section{Charge-Transfer adducts}

Most of the reported structurally characterized neutral CT adducts have sulfur as the donor atom and diiodine as the acceptor molecule [5, 11-61]. Those obtained from molecules containing selenium and diiodine are less numerous [14, $25,69-81$ ], while few adducts of S- and Se-donors with IBr [57-60, 62-67, 81-83] and ICl $[60,61,67,68,83,84]$ have been reported and structurally characterized in the literature. Three $\mathrm{Br}_{2}$ adducts of S-donors have been characterized by X-ray diffraction analysis $[65,94]$, and no CT adducts of Te-donors are known with any dihalogen or interhalogen.
The interaction between LE chalcogen-donor molecules $(\mathrm{E}=\mathrm{S}, \mathrm{Se})$ and $\mathrm{XY}$ dihalogens and interhalogens $(\mathrm{X}=\mathrm{Y}=$ $\mathrm{I}, \mathrm{Br} ; \mathrm{X}=\mathrm{I}, \mathrm{Y}=\mathrm{Br}, \mathrm{Cl}$ ) to give adducts containing an almost linear $\mathrm{E}-\mathrm{X}-\mathrm{Y}$ fragment can be seen as a charge-transfer process. It occurs via the transfer of charge density from a lone pair of electrons on the donor atom to the empty $\sigma^{*}$ orbital of the halogen species, producing a lowering in the $\mathrm{X}-\mathrm{Y}$ bond order. The consequent increase in the $\mathrm{X}-\mathrm{Y}$ bond length can be finely tuned by using donors of different strengths, which means changing either the chalcogen-donor atom or its chemical environment.

Under such circumstances, the $\mathrm{E}-\mathrm{X}$ and $\mathrm{X}-\mathrm{Y}$ bond distances should be strongly correlated in CT adducts. In fact, a scatter plot of $d(\mathrm{~S}-\mathrm{I})$ against $d(\mathrm{I}-\mathrm{I})$ distances (Figure 2) for all $\mathrm{I}_{2}$ adducts with sulfur-containing molecules (including those featuring $\mathrm{I}_{2}$ bridging two donor molecules, and those featuring chains of $\mathrm{I}_{2}$ molecules anchored to a donor molecule) shows a close relationship between these two distances $[63,65,68]$, which initially was defined as a hyperbola-like [24]. A similar relationship is found between $d(\mathrm{Se}-\mathrm{I})$ and $d(\mathrm{I}-\mathrm{I})$ for all $\mathrm{I}_{2}$ adducts with Se-donors (Figure 3) [65, 68]. Analogous relationships should be expected for $\mathrm{IBr}$ and $\mathrm{ICl}$ adducts with $\mathrm{S}$ - and Se-donors, but the number of the reported structures is so low that it is not possible yet to establish them conclusively. However, it is possible to demonstrate that the structural features of the 


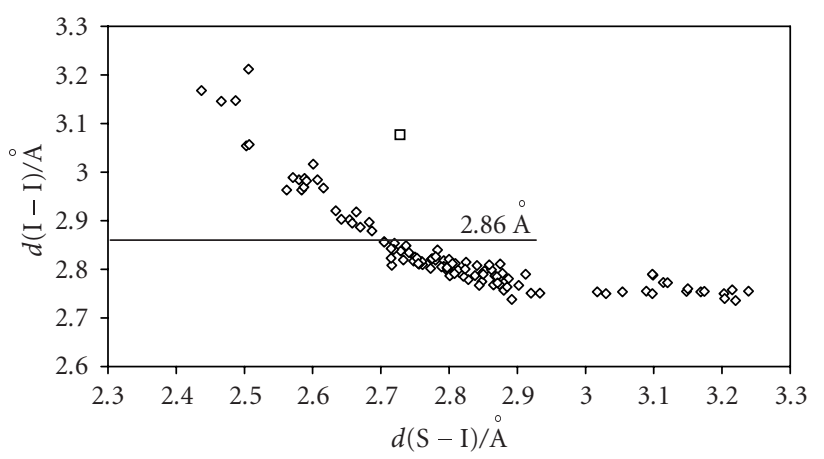

Figure 2: Scatter plot of $d(\mathrm{I}-\mathrm{I})$ versus $d(\mathrm{~S}-\mathrm{I})$ for all structurally characterized $\mathrm{I}_{2}$ adducts with $\mathrm{S}$-donors reported in the literature: $(\diamond)[5,11-44,46-61]$; benzimidazole-2(3H)-thione $\cdot I_{2}(\square)[45]$.

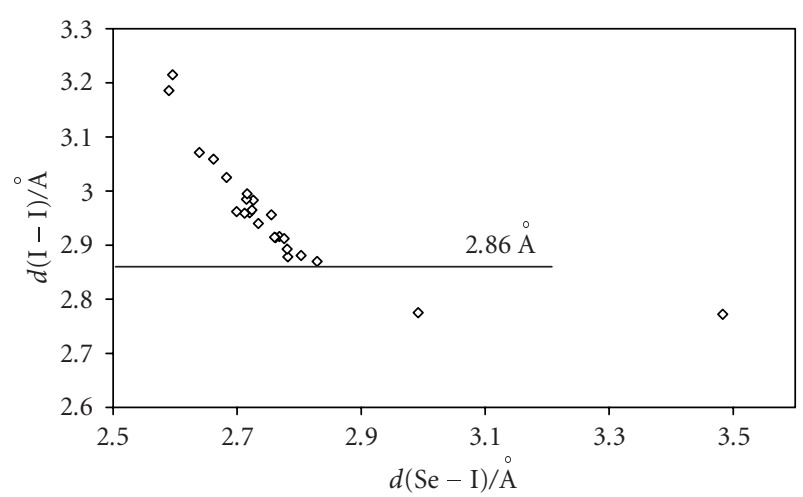

FIgURE 3: Scatter plot of $d(\mathrm{I}-\mathrm{I})$ versus $d(\mathrm{Se}-\mathrm{I})$ for all structurally characterized $\mathrm{I}_{2}$ adducts with Se-donors reported in the literature $[14,25,69-81]$.

$\mathrm{E}-\mathrm{I}-\mathrm{Y}$ moiety $(\mathrm{E}=\mathrm{S}, \mathrm{Se}, \mathrm{Y}=\mathrm{I}, \mathrm{Br}, \mathrm{Cl})$ for $\mathrm{I}_{2}, \mathrm{IBr}$, and $\mathrm{ICl}$ adducts are subject to the same kind of relationship, by considering the net increase in the $\mathrm{I}-\mathrm{Y}$ bond distances upon coordination $\Delta d(\mathrm{I}-\mathrm{Y})$ instead of the absolute $d(\mathrm{I}-\mathrm{Y})$ value $\left[\Delta d(\mathrm{I}-\mathrm{Y})=d(\mathrm{I}-\mathrm{Y})_{\text {adduct }}-d(\mathrm{I}-\mathrm{Y})_{\text {gas phase }}\right][63,65-$ 68]. In fact, the scatter plot of $\Delta d(\mathrm{I}-\mathrm{Y})$ versus $d(\mathrm{E}-\mathrm{I})$ (Figures 4 and 5) clearly indicate that for both $\mathrm{S}$ - and Se-donor molecules, the $d(\mathrm{E}-\mathrm{I})$ and $d(\mathrm{I}-\mathrm{Y})$ bond distances $(\mathrm{E}=\mathrm{S}$, Se; $\mathrm{Y}=\mathrm{I}, \mathrm{Br}, \mathrm{Cl}$ ) observed within CT adducts with IY acceptor molecules are correlated and show the same degree of variability.

The experimental data in Figures 4 and 5, except those for $\mathrm{I}_{2}$ adducts characterized by bridging $\mathrm{I}_{2}$ molecules (E-I distances lying between 3.01 and $3.30 \AA$ and I-I distances between 2.74 and $2.79 \AA, \mathrm{E}=\mathrm{S}, \mathrm{Se}$ ) [65] and the data for the adduct benzimidazole-2(3H)-thione $\cdot \mathrm{I}_{2}[45]$, can be fitted very well to the equation [66]

$$
\Delta d(\mathrm{I}-\mathrm{Y})=-b_{1} \ln \left\{1-\exp \left[\frac{\left(d_{0}(\mathrm{E}-\mathrm{I})-d(\mathrm{E}-\mathrm{I})\right)}{b_{2}}\right]\right\}
$$

obtainable by assuming a valence (bond order) model for the description of the $\mathrm{E}-\mathrm{I}-\mathrm{Y}$ system within $\mathrm{CT}$ adducts, with

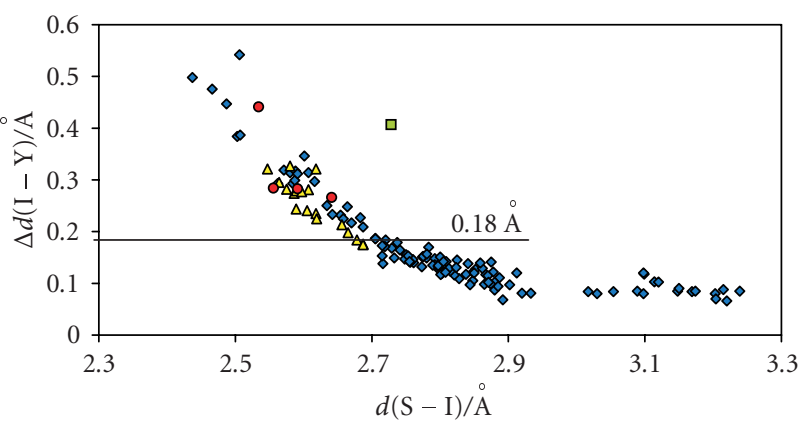

Figure 4: Scatter plot of $\Delta d(\mathrm{I}-\mathrm{Y})\left[\Delta d(\mathrm{I}-\mathrm{Y})=d(\mathrm{I}-\mathrm{Y})_{\text {adduct }}-d_{0}\right.$ $\left.(\mathrm{I}-\mathrm{Y})_{\text {gas phase }}(\mathrm{Y}=\mathrm{I}, \mathrm{Br}, \mathrm{Cl})\right]$ versus $d(\mathrm{~S}-\mathrm{I})[\mathrm{Y}=\mathrm{I}(\diamond)[5,11-44,46-$ 61], $\mathrm{Br}(\Delta)$ [57-60, 62-67, 81-83], $\mathrm{Cl}(\mathrm{o})[60,61,67,68,83,84]$; $d_{0}(\mathrm{I}-\mathrm{I})_{\text {gas phase }}=2.67 \AA[95], d_{0}(\mathrm{IBr})_{\text {gas phase }}=2.47 \AA$ [95], $d_{0}$ $\left.(\mathrm{ICl})_{\text {gas phase }}=2.32 \AA[95]\right]$; benzimidazole-2(3H)-thione $\cdot \mathrm{I}_{2}(\square)$ [45].

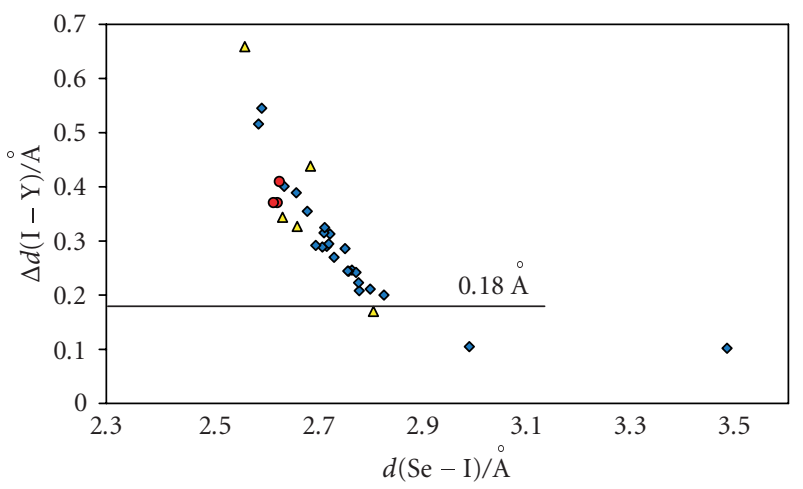

Figure 5: Scatter plot of $\Delta d(\mathrm{I}-\mathrm{Y})\left[\Delta d(\mathrm{I}-\mathrm{Y})=d(\mathrm{I}-\mathrm{Y})_{\text {adduct }}-\right.$ $\left.d_{0}(\mathrm{I}-\mathrm{Y})_{\text {gas phase }}(\mathrm{Y}=\mathrm{I}, \mathrm{Br}, \mathrm{Cl})\right][95]$ versus $d(\mathrm{Se}-\mathrm{I})[\mathrm{Y}=\mathrm{I}(\diamond)$ $[14,25,69-81], \operatorname{Br}(\Delta)$ [81-83], $\mathrm{Cl}(\mathrm{o})[68,83,84]]$.

$n(\mathrm{I}-\mathrm{Y})+n(\mathrm{E}-\mathrm{I})=1(\mathrm{E}=\mathrm{S}$, Se; $n=$ bond order $)[12,77]$, with $d_{0}(\mathrm{E}-\mathrm{I})=2.396 \AA$ and $2.528 \AA$ (experimental values for $\mathrm{E}=\mathrm{S}$, and Se, resp) [12], $b_{1}$ and $b_{2}$ are parameters.

The exclusion of the experimental data for $\mathrm{CT}_{2}$ adducts characterized by $\mathrm{I}_{2}$ bridging two-donor molecules from the fitting procedure is justified by the fact that these systems are very different from the usual $\mathrm{CT}$ adducts in terms of $\mathrm{MO}$ description. In fact, the consequence of extending the simple $\mathrm{n} \rightarrow \sigma^{*}$ description for the donor/acceptor interaction in terminal $\mathrm{I}_{2}$ adducts to a system in which an $\mathrm{I}_{2}$ molecule bridges two-donor molecules $\left(n \rightarrow \sigma^{*} \leftarrow n\right)$ is that only two electrons have a bonding nature, since the other two occupy a nonbonding orbital. However, these two bonding electrons are distributed over three bonds instead of over two, and much longer S ...I and shorter I-I bond distances are expected $[22,65]$. On the other hand, the fact that the structural data for the adduct benzimidazole-2 $(3 \mathrm{H})$-thione $\cdot \mathrm{I}_{2}$ do not fit the generalized $\Delta d(\mathrm{I}-\mathrm{Y})$ versus $d(\mathrm{~S}-\mathrm{I})$ correlation (Figures 2 and 4) can be accounted on the basis of the fact that, in this compound, the terminal iodine atom is strongly $\mathrm{H}$-bonded to an adjacent and symmetry-related adduct unit [45]. This interaction lengthens both the S-I and the I-I bonds with respect to the values generally observed in 
terminal $\mathrm{I}_{2}$ adducts. In fact, in this adduct, the sum of $\mathrm{S}-\mathrm{I}$ and $\mathrm{I}-\mathrm{I}$ distances is $5.81 \AA$, which is quite different from the value of $5.61 \pm 0.05 \AA[66]$ obtained by averaging the values for the other "spoke" $\mathrm{I}_{2}$ adducts reported in the literature $(5.34 \pm 0.03 \AA$ is the average value for the sum of $\mathrm{S}-\mathrm{I}$ and $\mathrm{I}-\mathrm{Br}$ in IBr adducts, $5.22 \AA$ is the average value for the sum of $\mathrm{S}-\mathrm{I}$ and $\mathrm{I}-\mathrm{Cl}$ in $\mathrm{ICl}$ adducts, whereas $5.70 \pm 0.04,5.53$, and $5.33 \AA$ are the average values for the corresponding sums for $\mathrm{I}_{2}, \mathrm{IBr}$, and $\mathrm{ICl}$ adducts with Se-donors, resp, standard deviation is reported only for mean values obtained by averaging a conspicuous number of data (more than 10)). Interestingly, for the adduct 5-chloro-benzimidazole$2(3 \mathrm{H})$-thione $\cdot \mathrm{I}_{2}[44]$, where the terminal iodine atom also participates in a strong hydrogen bond, the sum of S-I and $\mathrm{I}-\mathrm{I}$ distances is $5.55 \AA$, and the structural parameters very well fit the generalized $\Delta d(\mathrm{I}-\mathrm{Y})$ versus $d(\mathrm{~S}-\mathrm{I})$ correlation.

$\mathrm{CT} \mathrm{I}_{2}$ adducts (the most numerous) were classified into three categories $[34,65]$. (i) Weak or medium-weak adducts characterized by a mutual perturbation effect between the donor and the $\mathrm{I}_{2}$ molecules. The $\mathrm{I}-\mathrm{I}$ bond order $[n(\mathrm{I}-\mathrm{I})]$, defined by the equation $d(\mathrm{I}-\mathrm{I})=d_{0}-c \log n$ (where $d_{0}$ is the $\mathrm{I}-\mathrm{I}$ bond distance for $\mathrm{I}_{2}$ in the gas phase and $c$ is an empirical constant with a value of 0.85 ), in these systems ranges from values slightly lower than 1 (unperturbed $\mathrm{I}_{2}$ molecule, $d(\mathrm{I}-\mathrm{I})=2.715(6) \AA$ in the solid state) [96] to no less than $0.6(d(\mathrm{I}-\mathrm{I})<2.86 \AA)$. (ii) Strong adducts characterized by $n(\mathrm{I}-\mathrm{I})$ ranging between 0.4 and $0.6(2.86 \AA$ $<d(\mathrm{I}-\mathrm{I})<3.01 \AA)$. (iii) Very strong adducts in which the donor-acceptor interaction is so strong that $n(\mathrm{I}-\mathrm{I})$ becomes lower than $0.4(d(\mathrm{I}-\mathrm{I})>3.01 \AA)$. Figures 2 and 3 clearly show that $\mathrm{I}_{2}$ adducts with $\mathrm{S}$-donors are mainly weak adducts, whereas those with Se-donors are strong ones.

Considering the $\Delta d(\mathrm{I}-\mathrm{Y})$ parameter, this classification can be extended to $\mathrm{IBr}$ and $\mathrm{ICl}$ adducts under the approximation that the range of $\Delta d(\mathrm{I}-\mathrm{I})$ defining the three categories for $\mathrm{I}_{2}$ adducts are roughly valid also for $\mathrm{IBr}$ and $\mathrm{ICl}$ adducts: values of $\Delta d(\mathrm{I}-\mathrm{Y})$ lower than $0.18 \AA$ are indicative of weak or medium-weak adducts; $\Delta d(\mathrm{I}-\mathrm{Y})>0.34 \AA$ is indicative of a very strong donor/acceptor interaction; $0.18 \AA$ $<\Delta d(\mathrm{I}-\mathrm{Y})<0.34 \AA$ corresponds to strong adducts. Figures 4 and 5 clearly show that IBr and ICl adducts with both S- and Se-donors are strong adducts $[63,65,66,68]$.

This classification was initially introduced to bring order among FT-Raman data recorded for a large number of structurally characterized $\mathrm{I}_{2}$ adducts [97]. Indeed for weak or medium-weak $\mathrm{I}_{2}$ adducts $(d(\mathrm{I}-\mathrm{I})<2.86 \AA)$ a linear correlation was found between the measured $\nu(\mathrm{I}-\mathrm{I})$ Raman frequency and the I-I bond length, with $\nu(\mathrm{I}-\mathrm{I})$ shifted towards lower values (in the range $180-135 \mathrm{~cm}^{-1}$ ) as compared to the stretching frequency of $\mathrm{I}_{2}$ at the solid state $\left(180 \mathrm{~cm}^{-1}\right)$ [97] as a consequence of adduct formation (Figure 6). For strong $\mathrm{I}_{2}$ adducts, two main peaks are generally detected in their FT-Raman spectra, ascribable to the symmetric $\left(\nu_{1}, 120\right.$ $\left.115 \mathrm{~cm}^{-1}\right)$ and antisymmetric $\left(\nu_{3}, 145-125 \mathrm{~cm}^{-1}\right)$ stretching modes of the $\mathrm{E}-\mathrm{I}-\mathrm{I}$ three-body system $(\mathrm{E}=\mathrm{S}, \mathrm{Se})$; a much less intense peak in the range $100-80 \mathrm{~cm}^{-1}$ due to a bending mode $\left(v_{2}\right)$ is also observed (lower attention will be paid to this vibrational mode in this paper) $[65,71,81]$.

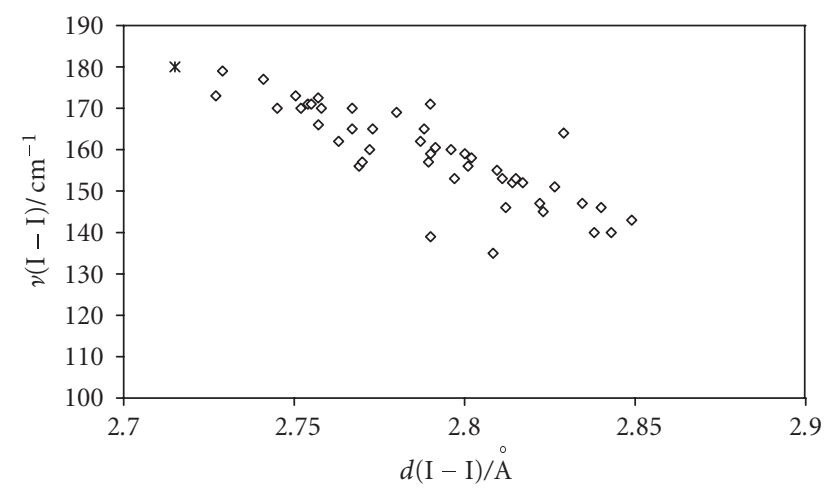

FIGURE 6: Scatter plot of $\nu(\mathrm{I}-\mathrm{I}) / \mathrm{cm}^{-1}$ versus $d(\mathrm{I}-\mathrm{I}) / \AA$ for weak or medium-weak adducts $(\diamond$, data from $[13,14,17-19,21,22,25,28$, $30-33,39,43-46,48,54-56,59,60,67])$, solid diiodine ( $*$ ) [97].

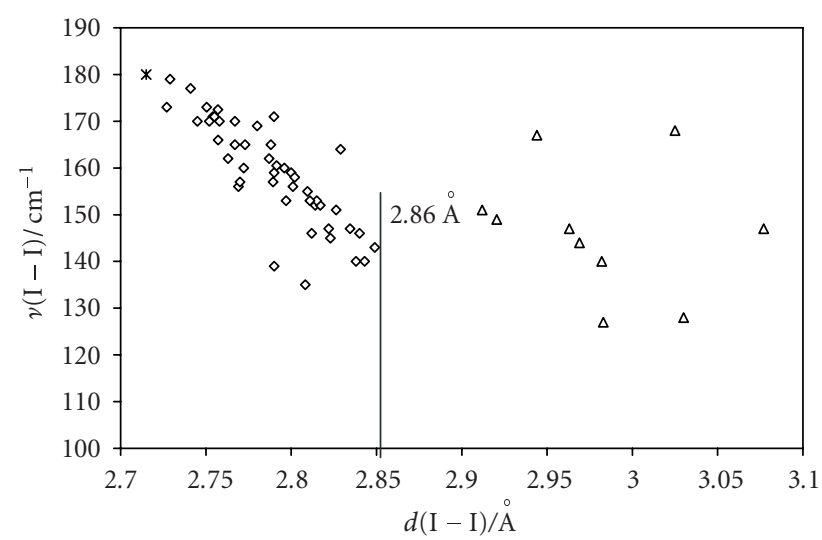

FIGURE 7: Scatter plot of $\nu(\mathrm{I}-\mathrm{I}) / \mathrm{cm}^{-1}$ versus $d(\mathrm{I}-\mathrm{I}) / \AA$ for weak or medium-weak adducts $(\diamond$, data from $[13,14,17-19,21,22,25,28$, 30-33, 39, 43-46, 48, 54-56, 59, 60, 67]), solid diiodine (*) [97], and strong adducts $(\Delta$, data from $[14,44,45,48,71,72,81,97])$.

Figure 7 clearly points out the differences in terms of FTRaman behavior between weak and strong $\mathrm{I}_{2}$ adducts; in fact, the antisymmetric $\left(v_{3}\right)$ stretching frequency (having a major contribution from the I-I stretching) observed for the strong adducts does not fall within the linear correlation $v(\mathrm{I}-\mathrm{I})$ versus $d(\mathrm{I}-\mathrm{I})$ found for weak $\mathrm{I}_{2}$ adducts. For $\mathrm{IBr}$ and $\mathrm{ICl}$ adducts, which are strong adducts according to the above classifications, much less structural and FT-Raman data are available, therefore generalizations are less reliable. $\mathrm{IBr}$ adducts with both S- and Se-donors show one main peak in their FT-Raman spectra in the range $190-140 \mathrm{~cm}^{-1}$ $[16,59,60,62-67,81]$ at a lower frequency with respect to solid $\mathrm{IBr}\left[216 \mathrm{~cm}^{-1}, d(\mathrm{I}-\mathrm{Br})=2.521(4) \AA\right]$ [98], and it is assignable to a stretching vibration of the $\mathrm{E}-\mathrm{I}-\mathrm{Br}$ threebody system having a major contribution from the $v(\mathrm{I}-\mathrm{Br})$ vibration [63]. ICl adducts (only four out of seven are both structurally and vibrationally characterized) $[60,67,68]$ generally show in their FT-Raman spectra two main peaks: one in the range $240-180 \mathrm{~cm}^{-1}$ presumably due to the antisymmetric $\left(\nu_{3}\right)$ stretching vibration of the $\mathrm{E}-\mathrm{I}-\mathrm{Cl}$ three 


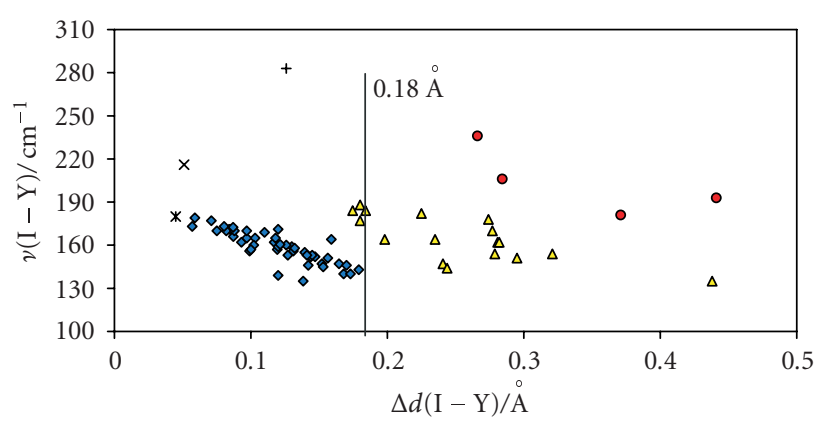

FIGURE 8: Scatter plot of $\nu(\mathrm{I}-\mathrm{Y}) / \mathrm{cm}^{-1}$ versus $\Delta d(\mathrm{I}-\mathrm{Y}) / \AA[\mathrm{Y}=\mathrm{I}(\diamond)$ $[13,14,17-19,21,22,25,28,30-33,39,43-46,48,54-56,59,60$, 67], $\mathrm{Br}(\Delta)[6,59,60,62-67,81], \mathrm{Cl}(\mathrm{o})[60,67,68]] . *$ = solid diiodine [97], $\times=$ solid IBr [98], $+=$ solid ICl [99].

body-system $(\mathrm{E}=\mathrm{S}, \mathrm{Se})$, and the other at about $130 \mathrm{~cm}^{-1}$ due to the symmetric $\left(\nu_{1}\right)$ stretching vibration (solid ICl is characterized by a single peak at $283 \mathrm{~cm}^{-1}$ in its FT-Raman spectrum with a $d(\mathrm{I}-\mathrm{Cl})=2.446(6) \AA)$ [99]. Interestingly, by considering the $\Delta d(\mathrm{I}-\mathrm{Y})$ parameter $(\mathrm{Y}=\mathrm{I}, \mathrm{Br}, \mathrm{Cl})$, a linear correlation appears also to exist between $\Delta d(\mathrm{I}-\mathrm{Br})$ and $v(\mathrm{I}-\mathrm{Br})$ for $\mathrm{IBr}$ adducts, and between $\Delta d(\mathrm{I}-\mathrm{Cl})$ and the $v(\mathrm{E}-\mathrm{I}-\mathrm{Cl})$ stretching mode corresponding to the $v_{\text {antisym }}$ in symmetric three-body systems, for ICl adducts (Figure 8).

Very few examples of very strong adducts with chalcogen donors are known, for which no vibrational characterization has been reported. Very strong adducts between group15 donors $(\mathrm{P}, \mathrm{As}, \mathrm{Sb})$ and dihalogens/interhalogens are more numerous [100-104]. The vibrational properties of these systems reflect the nature of the $[\mathrm{D}-\mathrm{X}]^{+}$cation interacting with a $\mathrm{Y}^{-}$anion $[100,101]$.

The classification for the CT adducts based on the I-Y bond order can also be extended to trihalides such as $\mathrm{XY}_{2}{ }^{-}$ $(\mathrm{X}=\mathrm{I}, \mathrm{Br} ; \mathrm{Y}=\mathrm{I}, \mathrm{Br}, \mathrm{Cl})$. In fact, these can be formally considered CT adducts between a $\mathrm{Y}^{-}$anionic Lewis base and an XY Lewis acid. Under this point of view, symmetrical or slightly asymmetrical trihalides can be considered belonging to the class of strong adducts, whereas strongly asymmetric trihalides can be considered belonging to the class of weak adducts. Spectroscopic implications of this are analyzed below. Usually a three-centre, four-electron $(3 c, 4 \mathrm{e})$ bonding scheme is applied to these triatomic anions. This accounts for the 0.5 bond order calculated in symmetric systems (the empty $p_{z}$ orbital of a 6-electron low-spin central $\mathrm{X}^{+}$cation interacts, in the $D_{\infty \mathrm{h}}$ point group, with the out-of-phase symmetry orbital combination $\left(\sigma_{\mathrm{u}}{ }^{+}\right.$in $\left.D_{\infty \mathrm{h}}\right)$ obtained from the lone pairs of two terminal $\mathrm{Y}^{-}$anions to produce a bonding and an antibonding MO, the other symmetry orbital combination $\left(\sigma_{\mathrm{g}}{ }^{+}\right.$in $\left.D_{\infty \mathrm{h}}\right)$ becoming a nonbonding orbital) [65]. Some authors have extended this description to the three-body system $\mathrm{E}-\mathrm{X}-\mathrm{Y}$ in $\mathrm{CT}$ adducts between chalcogen donors and dihalogens/interhalogens $[61,65]$, thus pointing out the strict structural and spectroscopic analogy of these compounds with trihalides. Before considering these analogies more in detail, it is better to describe from a structural and spectroscopic point of view the class of compounds known as polyiodides which apparently have nothing to share with CT adducts of chalcogen donors with dihalogens and interhalogens.

\section{TRIIODIDES AND HIGHER POLYIODIDES SPECIES}

It is well known that $I_{2}$ is the dihalogen having the highest ability to catenate, thus affording oligomeric polyanions which can assume a wide range of structural motifs $[105,106]$. This tendency to catenate decreases considerably on passing to dibromine and dichlorine [107].

Most of the known polyiodides have the general formula $\left(\mathrm{I}_{2 m+n}\right)^{n-}$ which formally implies the addition of $m \mathrm{I}_{2}$ molecules to $n$ iodide ions. Examples of small polyiodides belonging to this family, such as $\mathrm{I}_{3}{ }^{-}, \mathrm{I}_{4}{ }^{2-}$, and $\mathrm{I}_{5}{ }^{-}$, are very numerous in literature, but the occurrence of discrete $\mathrm{I}_{2}$ rich higher polyiodides (from $\mathrm{I}_{7}^{-}$to $\mathrm{I}_{22}{ }^{4-}$ ) becomes increasingly rare as $m$ and $n$ increase $[105,106]$. On the basis of structural data, all known higher discrete polyiodides can be considered derived from the donor/acceptor interaction of asymmetric $\mathrm{I}_{3}{ }^{-}$and/or $\mathrm{I}^{-}$with $\mathrm{I}_{2}$ molecules that emerge slightly elongated $\left[\mathrm{I}-\mathrm{I} \sim 2.75-2.80 \AA,\left(\mathrm{I}_{3}^{-}\right) \mathrm{I}^{-} \cdots \mathrm{I}_{2} \sim 3.2-\right.$ 3.6 $\mathrm{A}$. $\angle\left(\mathrm{I}_{3}{ }^{-}\right) \mathrm{I}^{-}-\mathrm{I}-\mathrm{I}$ bond angles are frequently observed at 90 or $180^{\circ}$ but can deviate considerably from these values with longer $\left(\mathrm{I}_{3}{ }^{-}\right) \mathrm{I}^{-} \cdots \mathrm{I}_{2}$ bond lengths. Polyiodides can be regarded, therefore, as weak or medium-weak adducts of the type $\left[\left(\mathrm{I}^{-}\right)_{n-y} \cdot\left(\mathrm{I}_{3}{ }^{-}\right)_{y} \cdot\left(\mathrm{I}_{2}\right)_{m-y}\right]$, whose geometrical and topological features can be very different and often unpredictable. Some of these polyiodides are present in the crystal lattice as discrete aggregates, but they frequently form polymeric chains or extended 2D or 3D networks in the polyanionic matrix via I . . I cross-linking soft-soft secondary interactions: these generally range from $3.6 \AA$ up to the van der Waals sum for two iodine atoms ( $4.3 \AA$ ), and the identification of the basic polyiodide unit can became arbitrary. This extraordinary ability of $\mathrm{I}_{2}, \mathrm{I}_{3}{ }^{-}$, and $\mathrm{I}^{-}$to interact with each other to give polyiodides is affected profoundly by the size, shape, and charge of the associated countercation, and these parameters have been considered in recent papers to achieve control over their 3D architecture [92, 105, 106, 108-110].

From the above, it is clear that in the absence of a crystal structure determination, it becomes very hard to guess the nature and the structural features of polyiodide anions. The FT-Raman spectroscopy can only give valuable information on the nature of their building blocks.

In the linear and symmetric $\mathrm{I}_{3}{ }^{-}$, the Raman-active symmetric stretch $\left(\nu_{1}\right)$ occurs near $110 \mathrm{~cm}^{-1}$, while the antisymmetric stretch $\left(\nu_{3}\right)$ and the bending deformation $\left(\nu_{2}\right)$ are only infrared-active. The latter two modes become Raman-active for asymmetric $\mathrm{I}_{3}{ }^{-}$, in which case they are found near 134 $\left(\nu_{3}\right)$ and $80 \mathrm{~cm}^{-1}\left(\nu_{2}\right)$, having medium and medium-weak intensities, respectively, as found for strong CT $\mathrm{I}_{2}$ adducts. For highly asymmetric $\mathrm{I}_{3}{ }^{-}$ions, which can be considered weak adducts between $\mathrm{I}^{-}$and $\mathrm{I}_{2}\left[\mathrm{I}^{-} \cdot \mathrm{I}_{2}\right]$, as found in neutral $\mathrm{I}_{2}$ adducts with S-donors, the FT-Raman spectrum shows only one strong band in the range $180-140 \mathrm{~cm}^{-1}$, indicative of the presence of a perturbed $\mathrm{I}_{2}$ molecule $[106,111,112]$.

As already mentioned, all the higher polyiodide species may be regarded as weak or medium-weak adducts of the 
type $\left[\left(\mathrm{I}^{-}\right)_{n-y} \cdot\left(\mathrm{I}_{3}^{-}\right)_{y} \cdot\left(\mathrm{I}_{2}\right)_{m-y}\right]$. Consequently, the corresponding FT-Raman spectra will show peaks due to perturbed diiodine molecules for $\left[\left(\mathrm{I}^{-}\right)_{n} \cdot\left(\mathrm{I}_{2}\right)_{m}\right]$ systems $(y=$ 0 ), and characteristic peaks due to both perturbed diiodine molecules and symmetric or slightly asymmetric $\mathrm{I}_{3}{ }^{-}$ions for polyiodies of the types $\left[\left(\mathrm{I}_{3}{ }^{-}\right)_{n} \cdot\left(\mathrm{I}_{2}\right)_{m-n}\right](n=y \neq 0)$ and $\left[\left(\mathrm{I}^{-}\right)_{n-y} \cdot\left(\mathrm{I}_{3}{ }^{-}\right)_{y} \cdot\left(\mathrm{I}_{2}\right)_{m-y}\right](n>y \neq 0)$. It is therefore evident that except for the presence or absence of symmetric and slightly asymmetric $\mathrm{I}_{3}{ }^{-}$units, the Raman technique is unable to distinguish between the different types of polyiodides or to discriminate unambiguously between the polyiodides and the neutral $\mathrm{I}_{2}$ adducts with chalcogen donors. However, it can give valuable information on the extent of the lengthening of the I-I bond, whether or not it has been produced by interaction of $I_{2}$ with a neutral donor or an ion. Furthermore, FT-Raman spectroscopy cannot give any structural information on the topological features of an extended polyiodide network as the technique cannot elucidate the structure beyond the basic polyiodide units in terms of combinations of $\mathrm{I}^{-}, \mathrm{I}_{2}$, and $\mathrm{I}_{3}{ }^{-}$units.

A further complication to the interpretation of FTRaman spectra of polyiodides may arise when the basic polyiodide unit sits on special crystallographic positions. For example, in $\left[\mathrm{Ag}\left([18] \mathrm{aneS}_{6}\right)\right] \mathrm{I}_{7}[113]$, the complex cation is embedded in a 3D polymeric polyiodide matrix of $\mathrm{I}_{7}{ }^{-}$anions. The overall structure of the $\left[\left(\mathrm{I}_{7}\right)^{-}\right]_{\infty}$ network can best be described as a distorted cube in which $\mathrm{I}^{-}$ions occupy the lattice points of a primitive rhombohedral lattice with one slightly elongated $\mathrm{I}_{2}$ molecule placed along each edge bridging two $\mathrm{I}^{-}$ions. Each $\mathrm{I}^{-}$interacts with six diiodine molecules arranged in a perfect $D_{3 \mathrm{~d}}$ symmetry. Because all six $\mathrm{I}_{2}$ molecules have the same I-I bond distance, only one peak should be present in the FT-Raman spectrum below $180 \mathrm{~cm}^{-1}$. However, the stretching vibrations of the six individual $\mathrm{I}_{2}$ units can combine, and in $D_{3 \mathrm{~d}}$ symmetry they give rise to two Raman-active normal modes of $A_{1 g}+E_{g}$ types. The observed bands at 179 and $165 \mathrm{~cm}^{-1}$ can therefore be assigned to these two modes, respectively. A lowering of the symmetry due to different bond distances for the two perturbed $\mathrm{I}_{2}$ units will split the $\mathrm{E}_{\mathrm{g}}$ mode, thus causing the appearance of three bands in the FT-Raman spectrum. Similarly, the case of the $\mathrm{I}_{5}{ }^{-}$ion with a $\mathrm{C}_{2 \mathrm{v}}$ symmetry in $\left[\operatorname{Ag}\left([9] \mathrm{aneS}_{3}\right)_{2}\right] \mathrm{I}_{5}[113]$ can be tackled: the vibrations of the two individual $\mathrm{I}_{2}$ units combine to give normal modes of the $\mathrm{A}_{1}+\mathrm{B}_{2}$ types. A lowering of the symmetry due to different bond distances for the two perturbed $\mathrm{I}_{2}$ units will increase the energy of the higher energetic stretching normal mode and lower the energy of the lower energetic stretching normal mode.

It may also happen that polyiodides are unstable under the laser beam and cause spurious peaks to appear in their Raman spectra. This is more likely using visible excitation sources and resonance Raman spectroscopy; using near-infrared laser excitation sources and FT-Raman spectroscopy, such problems, particularly fluorescence and photoreactions, can be considerably reduced. Nevertheless, decomposition of polyiodides during spectrum acquisition must be always considered and ascertained before passing on to the assignment of the FT-Raman bands in order to avoid confusion with the scattering from decomposition products (generally driven from loss of diiodine molecules).

After this concise overview on polyiodides, it is worthy to point out the vibrational analogies in terms of FT-Raman that can exist between $\mathrm{I}_{3}{ }^{-}$and $\mathrm{I}_{2}$ adducts with chalcogen donors.

Strong CT $\mathrm{I}_{2}$ adducts, in particular those formed by Sedonors, present two main peaks in their FT-Raman spectra assigned to the antisymmetric and symmetric stretching modes of the Se-I-I three-body system (see above). The observed frequencies are very close to those normally recorded for asymmetric triiodides. On the other hand, weak or medium-weak CT $\mathrm{I}_{2}$ adducts, in particular those with Sdonors, present only one peak in their FT-Raman spectra assigned to the stretching mode of the perturbed diiodine molecule (see above). The observed frequency is indistinguishable from that recorded for very asymmetric triiodides. Thus the groups $\mathrm{Se}-\mathrm{I}-\mathrm{I}$ and $(\mathrm{I}-\mathrm{I}-\mathrm{I})^{-}$, and $\mathrm{S} \cdots \mathrm{I}-\mathrm{I}$ and $\mathrm{I}^{-} \ldots$ I-I give very similar FT-Raman spectra. This fact can produce confusion when chalcogen donors are reacted with diiodine, and no X-ray diffraction analysis of the products is available: the formation of a triiodide, and, more broadly of a polyiodide, can be erroneously invoked in the presence of neutral adducts and vice versa.

\section{HYPERVALENT CHALCOGEN COMPOUNDS}

The pivotal role of the vibrational properties of $\mathrm{I}_{3}{ }^{-}$and other trihalides in the assignment of the FT-Raman peaks for the products obtained by reacting chalcogen donors with dihalogens/interhalogens is even clearer by considering the class of hypervalent compounds.

Hypervalent chalcogen compounds featuring a linear $\mathrm{X}-\mathrm{E}-\mathrm{Y}$ moiety $[\mathrm{X}=\mathrm{Y}=\mathrm{I}, \mathrm{Br}, \mathrm{Cl} ; \mathrm{X}=\mathrm{I}, \mathrm{Y}=\mathrm{Br}, \mathrm{Cl}$; $\mathrm{E}=$ $\mathrm{S}$, Se] can be considered to derive formally from the oxidative addition of an $\mathrm{X}_{2}$ or $\mathrm{XY}$ molecule to the donor molecule containing the chalcogen atom. With donors of the types $\mathrm{R}_{2} \mathrm{C}=\mathrm{E}$ $(\mathrm{E}=\mathrm{S}, \mathrm{Se})$ and $\mathrm{R}_{2} \mathrm{E}(\mathrm{E}=\mathrm{S}, \mathrm{Se})$, the structural features of the corresponding adducts is well explained by the VSEPR model, according to which the geometry at the chalcogen atom is a pseudotrigonal bipyramid (tbp) with the halogens occupying the apical positions, in the case of $\mathrm{R}_{2} \mathrm{C}=\mathrm{E}$ donors (two lone pairs and one bond pair in the plane perpendicular to the $\mathrm{X}-\mathrm{E}-\mathrm{Y}$ direction), and disphenoidal in the case of $\mathrm{R}_{2} \mathrm{E}$ ones (one lone pair and two bond pairs in the plane perpendicular to the $\mathrm{X}-\mathrm{E}-\mathrm{Y}$ direction). These compounds are commonly referred to as, respectively, $10-\mathrm{E}-4$ and $10-\mathrm{E}-3$ systems, indicating that the chalcogen atom $\mathrm{E}$ is formally associated with five pairs of electrons, only four or three of which are bond pairs (Figure 9), respectively [114]. As with a trihalide or a CT adduct (see above), the chemical bond in the $\mathrm{X}-\mathrm{E}-\mathrm{Y}$ fragment can be described using the $3 \mathrm{c}$, 4e bonding scheme, which implies a total bond order of 1 (0.5-bond order for each $\mathrm{E}-\mathrm{X}$ bond in symmetric systems). This description agrees with the qualitative observation that on increasing the electronegativity difference between the halogen and the chalcogen, hypervalent chalcogen adducts are formed 


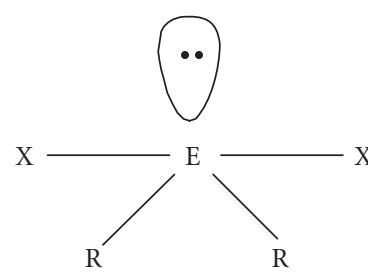

$10-\mathrm{E}-4$

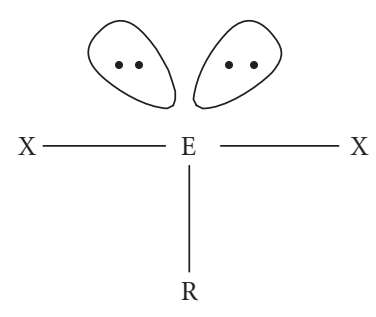

$10-\mathrm{E}-3$
FIGURE 9: Schematic representation of 10-E-4 and 10-E-3 hypervalent chalcogen compounds $(\mathrm{E}=\mathrm{S}, \mathrm{Se}, \mathrm{Te})$.

more easily than $\mathrm{CT}$ adducts bearing an $\mathrm{E}-\mathrm{X}-\mathrm{Y}$ linear group on reacting chalcogen donors with dihalogens and interhalogens. Indeed, no hypervalent sulfur compounds containing the I-S-I moiety are known, and only three hypervalent selenium compounds containing the $\mathrm{I}-\mathrm{Se}-\mathrm{I}$ framework have recently been structurally characterized [71, 115]. Only three examples of a $\mathrm{Br}-\mathrm{S}-\mathrm{Br}$ type hypervalent sulfur compound with dibromine have been structurally characterized $[59,88,116]$, while analogous compounds from selenium containing substrates are numerous $[65,69,85,88,117]$. As expected, hypervalent sulfur and selenium compounds containing the linear $\mathrm{Cl}-\mathrm{E}-\mathrm{Cl}(\mathrm{E}=\mathrm{S}, \mathrm{Se})$ group are very well known $[65,69,86]$. For the oxidative addition of interhalogens (IBr, ICl), only two examples of "T-shaped" adducts featuring $\mathrm{I}-\mathrm{E}-\mathrm{Br}(\mathrm{E}=\mathrm{S}, \mathrm{Se})$ moieties are known (for the hypervalent compound featuring the $\mathrm{I}-\mathrm{S}-\mathrm{Br}$ fragment, no $\mathrm{X}$-ray characterization is reported) $[89,116]$.

The strict analogy between trihalides and hypervalent chalcogen compounds is clearly pointed out also by the $\mathrm{Ra}$ man spectroscopy. In fact, it has been shown that hypervalent Se-compounds featuring a linear $\mathrm{I}-\mathrm{Se}-\mathrm{I}$ moiety show in the low-frequency region of their FT-Raman spectra one or two peaks depending on whether the I-Se-I fragment is symmetric or slightly asymmetric, which are very similar to those arising from a symmetric or asymmetric $\mathrm{I}_{3}{ }^{-}$[71]. Therefore, the groups $\mathrm{Se}-\mathrm{I}-\mathrm{I}$ (strong adducts), (I-I-I)- (triiodides), and I-Se-I (hypervalent compounds) can be undistinguishable from a Raman point of view.

The same analogy is also found for hypervalent chalcogen compounds featuring a $\mathrm{Br}-\mathrm{E}-\mathrm{Br}$ linear system $(\mathrm{E}=$ $\mathrm{S}, \mathrm{Se})$. In fact, the vibrational properties of a $\mathrm{Br}-\mathrm{E}-\mathrm{Br}$ group resemble those of $(\mathrm{Br}-\mathrm{X}-\mathrm{Br})^{-}$anions $(\mathrm{X}=\mathrm{I}, \mathrm{Br})$ $[65,66,88,117]$. The FT-Raman spectrum of a symmetrical $\mathrm{Br}-\mathrm{E}-\mathrm{Br}$ group only shows one Raman peak near $160 \mathrm{~cm}^{-1}$ (see Figure 10), as found in symmetric $\mathrm{Br}_{3}{ }^{-}$and $\mathrm{IBr}_{2}{ }^{-}$anions, which can be assigned to the symmetric stretching vibration of the three-body system. Asymmetric $\mathrm{Br}-\mathrm{E}-\mathrm{Br}$ groups display an additional and generally less intense peak at around $190 \mathrm{~cm}^{-1}$ (see Figure 11), as found for asymmetric $\mathrm{Br}_{3}{ }^{-}$and $\mathrm{IBr}_{2}{ }^{-}$anions, which is assigned to the antisymmetric stretching vibration of the $\mathrm{Br}-\mathrm{E}-\mathrm{Br}$ or $(\mathrm{Br}-\mathrm{X}-\mathrm{Br})^{-}$ three-body systems $(\mathrm{E}=\mathrm{S}$, Se; $\mathrm{X}=\mathrm{I}, \mathrm{Br})$. These analogies are quite evident from Figures 10 and 11 [118]. Unfortunately, in the literature no spectroscopic data are available for

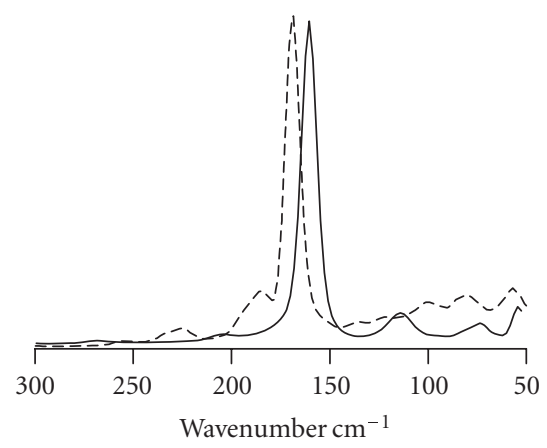

Figure 10: Superimposed FT-Raman spectra of the symmetric Se-hypervalent adduct $N, N^{\prime}$-dimethylbenzimidazole- $2(3 \mathrm{H})$ selone $\cdot \mathrm{Br}_{2}$ (full line) and the salt $\left(\mathrm{HL}^{\prime}\right)^{+} \mathrm{Br}_{3}{ }^{-}$(2, 4, 6-tris $(2-$ pyridyl)-1,3,5-triazinium tribromide, dashed line) featuring a symmetric $\mathrm{Br}_{3}{ }^{-}$[118].

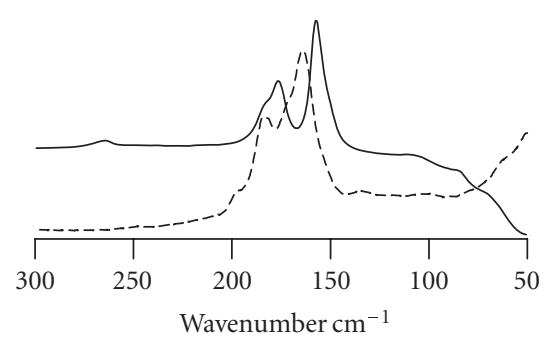

FIGURE 11: Superimposed FT-Raman spectra of the asymmetric Se-hypervalent adduct $N, N^{\prime}$-dimethylimidazolidine-2-selone $\cdot \mathrm{Br}_{2}$ (full line) and the salt $\left(\mathrm{H}_{2} \mathrm{~L}^{\prime}\right)^{2+} \mathrm{Br}^{-} \mathrm{IBr}_{2}{ }^{-}$(2, 2' -dipyridinium disulfide bromide iododibromide, dashed line) featuring an asymmetric $\mathrm{IBr}_{2}{ }^{-}[118]$.

chalcogen-hypervalent $\mathrm{Cl}_{2}$ adducts, thus preventing a structural/vibrational comparison of the $\mathrm{Cl}-\mathrm{E}-\mathrm{Cl}(\mathrm{E}=\mathrm{S}, \mathrm{Se})$ framework with the anions $(\mathrm{Cl}-\mathrm{X}-\mathrm{Cl})^{-}(\mathrm{X}=\mathrm{I}, \mathrm{Br})$. Overall, we can say that strong $\mathrm{I}_{2}$ adducts (generally deriving from Se-donors), $\mathrm{XY}_{2}{ }^{-}$trihalides (X $=\mathrm{I}, \mathrm{Br} ; \mathrm{Y}=\mathrm{I}, \mathrm{Br}, \mathrm{Cl}$ ), and hypervalent chalcogen compounds featuring a linear $\mathrm{X}-\mathrm{E}-\mathrm{X}$ moiety ( $\mathrm{X}=\mathrm{I}, \mathrm{Br}, \mathrm{Cl}$; $\mathrm{E}=\mathrm{S}, \mathrm{Se}$ ) can all be described with the same MO bonding scheme $(3 c, 4 e)$ and show very similar vibrational properties whose features depend on whether they are symmetric or asymmetric. On the other hand, weak $\mathrm{I}_{2}$ adducts (generally feturing S-donors) have FT-Raman spectra similar to those recorded for very asymmetric triodides or polyiodides of the type $\left[\left(\mathrm{I}^{-}\right)_{n} \cdot\left(\mathrm{I}_{2}\right)_{m}\right]$.

\section{TWO CHALCOGEN-COORDINATED HALOGEN(I) COMPLEXES}

Salts of two-chalcogen-coordinated halogen(I) complexes $\left[(\mathrm{LE}-\mathrm{X}-\mathrm{EL})^{+}\right]$can be formally considered as a central $\mathrm{X}^{+}$ $(\mathrm{X}=\mathrm{I}, \mathrm{Br}, \mathrm{Cl})$ coordinated by two donor molecules. The chemical bond in the resulting $\mathrm{E}-\mathrm{X}-\mathrm{E}$ almost-linear framework can be described according to $3 \mathrm{c}, 4 \mathrm{e}$ bonding scheme, as for CT adducts, trihalides, and hypervalent chalcogen compounds. So far, only cations of this kind formally featuring a 
central $\mathrm{I}^{+}$interacting with either S- or Se-donors have been isolated from the direct reaction of chalcogen donors and dihalogens (see Devillanova et al in this issue of BC\&A), and have been structurally characterized $[43,45,65]$. Similarly to what is observed for the three-body system in CT adducts $(\mathrm{E}-\mathrm{I}-\mathrm{Y}, \mathrm{E}=\mathrm{S}, \mathrm{Se}$; Y = I, Br, Cl), trihalides $(\mathrm{X}-\mathrm{I}-\mathrm{X}, \mathrm{X}=$ $\mathrm{I}, \mathrm{Br}, \mathrm{Cl})$, and hypervalent compounds $(\mathrm{X}-\mathrm{E}-\mathrm{X}, \mathrm{E}=\mathrm{S}, \mathrm{X}=$ $\mathrm{Br}, \mathrm{Cl} ; \mathrm{E}=\mathrm{Se}, \mathrm{X}=\mathrm{I}, \mathrm{Br}, \mathrm{Cl}$ ), also in these cations there is a correlation between the two $\mathrm{E}-\mathrm{I}$ bond distances $(\mathrm{E}=\mathrm{S}, \mathrm{Se})$ : the reinforcement of one $\mathrm{I}-\mathrm{E}$ bond corresponds to a lengthening of the other, the total length of the E-I-E framework being almost independent of the nature of the substrate incorporating the chalcogen. The mean value of the $\mathrm{E} \cdots \mathrm{E}$ distance is $5.28 \AA$ for $\mathrm{S}-\mathrm{I}-\mathrm{S}$ and $5.50 \AA$ for $\mathrm{Se}-\mathrm{I}-\mathrm{Se}$ systems (these distances are very similar, resp, to the averaging value for the sums of $\mathrm{S}-\mathrm{I}$ and $\mathrm{I}-\mathrm{Cl}$ in $\mathrm{ICl}$ adducts with $\mathrm{S}$-donors $(5.22 \AA)$, and $\mathrm{Se}-\mathrm{I}$ and $\mathrm{I}-\mathrm{Br}$ in $\mathrm{IBr}$ adducts with Se-donors $(5.53 \AA))$.

Unfortunately, very few spectroscopic data are available for iodonium salts in the literature, and generally the FT-Raman spectra are dominated by the absorption peaks due to the polyiodide counteranions. Therefore, a structural/vibrational relationship cannot be established. However, on the grounds of what has been said, and considering $\mathrm{S} / \mathrm{Cl}$ and $\mathrm{Se} / \mathrm{Br}$ mass similarities, the Raman peaks for the stretching vibrations of the $\mathrm{E}-\mathrm{I}-\mathrm{E}(\mathrm{E}=\mathrm{S}, \mathrm{Se})$ threebody systems could fall, depending on the organic framework, at frequencies reasonably close to those observed for $\mathrm{ICl}$ adducts with $\mathrm{S}$-donors or $\mathrm{ICl}_{2}{ }^{-}$trihalides $(\mathrm{E}=\mathrm{S})$, and $\mathrm{IBr}$ adducts with Se-donors or $\mathrm{IBr}_{2}{ }^{-}$trihalides $(\mathrm{E}=\mathrm{Se})$.

\section{CONCLUSIONS}

The results reviewed in this paper clearly point out that the reactions of chalcogen donors with dihalogens or interhalogens can afford a great variety of products depending on the nature of the donor, the reaction molar ratio, and the experimental conditions (solvent and temperature). In the absence of an X-ray diffraction analysis, the FT-Raman spectroscopy can be of help in elucidating the nature of the products obtained. However, much attention must be paid in the assignment of the Raman peaks recorded in order not to make confusion. In fact, the vibrational behavior in the lowfrequency region is sometimes undistinguishable for very similar three-body systems: $\mathrm{E}-\mathrm{I}-\mathrm{Y}(\mathrm{E}=\mathrm{S}, \mathrm{Se} ; \mathrm{Y}=\mathrm{I}, \mathrm{Br}, \mathrm{Cl})$ in CT adducts, $\mathrm{X}-\mathrm{E}-\mathrm{X}(\mathrm{E}=\mathrm{S}, \mathrm{X}=\mathrm{Br}, \mathrm{Cl} ; \mathrm{E}=\mathrm{Se}$, $\mathrm{X}=\mathrm{I}, \mathrm{Br}, \mathrm{Cl})$ in hypervalent chalcogen compounds, and $\mathrm{E}-\mathrm{I}-\mathrm{E}(\mathrm{E}=\mathrm{S}, \mathrm{Se})$ in two chalcogen-coordinated halogen $(\mathrm{I})$ complexes, which can all be described according to a $3 \mathrm{c}, 4 \mathrm{e}$ bonding scheme. Very recently, a vibrational analogy has also been found between $\mathrm{I}_{2}$ adducts of Se-donors and complexes of bidentate phosphate selenide ligands with mesitylenetellurenyl iodide featuring a $\mathrm{Se}-\mathrm{Te}-\mathrm{I}$ linear systems [119]. The problem is even more complex if the vibrational analogy with trihalides $\mathrm{IY}_{2}^{-}(\mathrm{Y}=\mathrm{I}, \mathrm{Br}, \mathrm{Cl})$ is considered. For example, the groups $\mathrm{Se}-\mathrm{I}-\mathrm{I}$ (strong adducts), $\mathrm{I}_{3}{ }^{-}$(asymmetric triiodides), and I-Se-I (hypervalent compounds) are undistinguishable from a Raman point of view, as well as the
$\mathrm{Br}-\mathrm{E}-\mathrm{Br}$ group $(\mathrm{E}=\mathrm{S}, \mathrm{Se})$ being vibrationally very similar to $\mathrm{Br}_{3}{ }^{-}$and $\mathrm{IBr}_{2}{ }^{-}$anions.

\section{ACKNOWLEDGMENT}

We thank all the collaborators listed in the references for their invaluable contributions to this work.

\section{REFERENCES}

[1] Raby C, Lagorce JF, Jambut-Absil AC, Buxeraud J, Catanzano G. The mechanism of action of synthetic antithyroid drugs: iodine complexation during oxidation of iodide. Endocrinology. 1990;126:1683-1691.

[2] du Mont W-W, Mugesh G, Wismach C, Jones PG. Reactions of organoselenenyl iodides with thiouracil drugs: an enzyme mimetic study on the inhibition of iodothyronine deiodinase. Angewandte Chemie - International Edition. 2001;40(13):2486-2489.

[3] Aragoni MC, Arca M, Demartin F, et al. Anti-thyroid drug methimazole: X-ray characterization of two novel ionic disulfides obtained from its chemical oxidation by $\mathrm{I}_{2}$. Journal of the American Chemical Society. 2002;124(17):4538-4539.

[4] Bigoli F, Deplano P, Mercuri ML, et al. $N, N^{\prime}$ dimethylpiperazinium-2,3-dithione triiodide, $\left[\mathrm{Me}_{2}\right.$ pipdt $] \mathrm{I}_{3}$, as a powerful new oxidation agent toward metallic platinum. Synthesis and $\mathrm{x}$-ray structures of the reagent and the product $\left[\mathrm{Pt}\left(\mathrm{Me}_{2} \text { pipdt }\right)_{2}\right]\left(\mathrm{I}_{3}\right)_{2}$. Journal of the American Chemical Society. 2001;123(8):1788-1789.

[5] Serpe A, Bigoli F, Cabras MC, et al. Pd-dissolution through a mild and effective one-step reaction and its application for Pd-recovery from spent catalytic converters. Chemical Communications. 2005;(8):1040-1042.

[6] Cau L, Deplano P, Marchiò L, et al. New powerful reagents based on dihalogen $/ \mathrm{N}, N^{\prime}$ - dimethylperhydrodiazepine-2,3dithione adducts for gold dissolution: the IBr case. Dalton Transactions. 2003;(10):1969-1974.

[7] Abbati GL, Aragoni MC, Arca M, et al. Oxidation of palladium powder by the adduct $\mathrm{Ph}_{2} \mathrm{P}(\mathrm{S}) \mathrm{NHP}(\mathrm{S}) \mathrm{Ph}_{2} \mathrm{I}_{2}$. Crystal structure of $\mathrm{PdL}_{2}$. Journal of the Chemical Society, Dalton Transactions. 2001;(7):1105-1110.

[8] Abbati GL, Aragoni MC, Arca M, et al. Gold(0) and Gold(III) reactivity towards the tetraphenyldithioimidodiphosphinic acid, $\left[\mathrm{Ph}_{2} \mathrm{P}(\mathrm{S}) \mathrm{NHP}(\mathrm{S}) \mathrm{Ph}_{2}\right]$. European Journal of Inorganic Chemistry. 2005;(3):589-596.

[9] Aragoni MC, Arca M, Carrea MB, et al. Copper(I) complexes with a $\mathrm{Cu}_{4} \mathrm{~S}_{6}$ - and $\mathrm{CuS}_{4}$-type core obtained from the reaction of copper $(0)$ with $\mathrm{HN}\left(\mathrm{SPPh}_{2}\right)_{2} \cdot \mathrm{I}_{2}$. European Journal of Inorganic Chemistry. 2006;(1):200-206.

[10] Ferraro JR, Williams JM. Introduction to Synthetic Electrical Conductors. New York, NY: Academic Press; 1987.

[11] Näther C, Bolte M. Investigations on the interaction between $\mathrm{sp}^{2}$-sulfur atoms and iodine molecules using the Cambridge structural database. Phosphorus, Sulfur and Silicon and the Related Elements. 2003;178(3):453-464.

[12] Ouvrard C, Le Questel J-Y, Berthelot M, Laurence C. Halogen-bond geometry: a crystallographic database investigation of dihalogen complexes. Acta Crystallographica Section B. 2003;59(4):512-526.

[13] Chao GY, McCullough JD. The refinement of the structure of the complex of iodine with 1,4 dithiane, $\mathrm{C}_{4} \mathrm{H}_{8} \mathrm{~S}_{2} \cdot 2 \mathrm{I}_{2}$. Acta Crystallographica. 1960;13(9):727-732. 
[14] Arca M, Cristiani F, Devillanova FA, et al. Reactivity of 1,3,5-trithiacyclohexane and 1,3,5-triselenacyclohexane towards molecular diiodine. Crystal structures of the diiodine adducts. Polyhedron. 1997;16(12):1983-1991.

[15] Rømming C. The crystal structure of the 1:1 addition compound formed by benzyl sulphide and iodine. Acta Chemica Scandinavica. 1960;14:2145-2151.

[16] Herbstein FH, Ashkenazi P, Kaftory M, Kapon M, Reisner GM, Ginsburg D. Propellanes LXXIX. Comparison of the geometries of dithia[n.3.3]propellanes $(n=1,2,3)$ and dithia(and oxathia) [4.3.3] propellanes. Study of the influence of complexation with $\mathrm{HgCl}_{2}, \mathrm{I}_{2}, \mathrm{CdCl}_{2}$ and $\mathrm{PdCl}_{2}$ and of formation of sulfoxides on some of these compounds. Demonstration of the 'Klammer' effect. Structures of eighteen crystals. Acta Crystallographica Section B. 1986;42:575-601.

[17] Tipton AL, Lonergan MC, Stern CL, Shriver DF. Structure, conductivity and Raman spectrum of 4,7,13,16-tetraoxa1,10-dithiacyclooctadecanebis(diiodine). Inorganica Chimica Acta. 1992;201(1):23-27.

[18] Cristiani F, Devillanova FA, Isaia F, Lippolis V, Verani G, Demartin F. Spectroscopic studies and X-ray crystal structures of charge-transfer complexes of 1,4,7-trithiacyclononane with diiodine. Heteroatom Chemistry. 1993;4(6):571-578.

[19] Blake AJ, Cristiani F, Devillanova FA, et al. Structural and solution studies of diiodine charge-transfer complexes of thioether crowns. Journal of the Chemical Society, Dalton Transactions. 1997;(8):1337-1346.

[20] Baker PK, Harris SD, Durrant MC, Hughes DL, Richards RL. Preparation and structural characterization of the chargetransfer complex $\left([12] \mathrm{aneS}_{4} \cdot \mathrm{I}_{2}\right)_{\infty}\left(12[\right.$ ane $] \mathrm{S}_{4}=1,4,7,10$ Tetrathiacyclododecane). Acta Crystallographica Section C. 1995;51(4):697-700.

[21] Blake AJ, Li W-S, Lippolis V, Schröder M. 1,4,8,11Tetrakis(diiodine)-1,4,8,11-tetrathiacyclotetradecane. Acta Crystallographica Section C. 1997;53(7):886-888.

[22] Blake AJ, Devillanova FA, Garau A, et al. Thioether-iodine charge-transfer complexes. Synthesis and low-temperature single-crystal structures of complexes of penta-, hexa-and octa-dentate homoleptic thioether macrocycles. Journal of the Chemical Society, Dalton Transactions. 1998;(12):20372046.

[23] Bock H, Nagel N, Seibel A. Interactions in molecular crystals, 123: crystallization and structure of donor-acceptor complexes between rigid or conformationally flexible thiocrowns and iodine. Liebigs Annales. 1997;(10):2151-2159.

[24] Herbstein FH, Schwotzer W. Crystal structures of polyiodide salts and molecular complexes. 7. Interaction of thiones with molecular diiodine. The crystal structures of dithizonediiodine, ethylenethiourea-bis(diiodine), bis(ethylenethiourea)-tris(diiodine), bis(dithizone)-heptakis(diiodine), and 1(1-imidazolin-2-yl)-2-thioxoimidazolidinium triiodide-(ethylenethiourea-diiodine). Journal of the American Chemical Society. 1984;106(8):2367-2373.

[25] Cristiani F, Demartin F, Devillanova FA, Isaia F, Saba G, Verani G. An X-ray, spectroscopic and semiempirical quantummechanical study on complexes of thiones and selones with molecular diiodine. Journal of the Chemical Society, Dalton Transactions. 1992;(24):3553-3560.

[26] Ahlsen EL, Strømme KO. The crystal structure of the addition compound $N$-methylthiocaprolactam-iodine (1:1). Acta Chemica Scandinavica - Series A. 1974;28:175-184.

[27] Freeman F, Ziller JW, Po HN, Keindl MC. Reactions of imidazole-2-thiones with molecular iodine and the struc- tures of two crystalline modifications of the 1:1 1,3-dimethylimidazole-2-thione-diiodine charge-transfer complex $\left(\mathrm{C}_{5} \mathrm{H}_{8} \mathrm{I}_{2} \mathrm{~N}_{2} \mathrm{~S}\right)$. Journal of the American Chemical Society. 1988;110(8):2586-2591.

[28] Atzei D, Deplano P, Trogu EF, Bigoli F, Pellinghelli MA, Vacca A. Interaction of diiodine with some tetra-substituted dithiooxamides. Crystal and molecular structure of bis(morpholinothiocarbonyl)bis(diiodine). Canadian Journal of Chemistry. 1988;66(6):1483-1489.

[29] Lu FL, Keshavarz KM, Srdanov G, Jacobson RH, Wudl F. A new preparation of 5-(alkylthio)-1,2-dithiole-3-thiones and a highly functionalized 1,3-dithiole-2-thione. The Journal of Organic Chemistry. 1989;54(9):2165-2169.

[30] Bigoli F, Deplano P, Mercuri ML, et al. Evaluation of thermodynamic parameters on higly correlated chemical systems: a spectrophotometric study of the $1: 1$ and 1:2 equilibria between $\mathrm{I}_{2}$ and $\mathrm{R}_{4}$ todit $=4,5,6,7$ tetrathiocino $[1,2-b$ : $3,4-b^{\prime}$ ]diimidazolyl-1,3,8,10-tetraalkyl-2,9-dithione; $(\mathrm{R}=$ $\mathrm{Bu}, \mathrm{Me}$ (new data); Et, Ph (reinvestigation)). Crystal and molecular structure of the charge-transfer complex Bu $\mathrm{Bu}_{4}$ todit . $2 \mathrm{I}_{2}$. Canadian Journal of Chemistry. 1995;73(3):380-388.

[31] Atzei D, Deplano P, Trogu EF, et al. Interaction of diiodine with $\mathrm{Et}_{4}$ todit $=4,5,6,7$-tetrathiocino $[1,2-b: 3,4-$ $b^{\prime}$ ] diimidazolyl-1,3,8,10-tetraethyl-2,9-dithione. Crystal and molecular structure of $\mathrm{Et}_{4}$ todit $\cdot 2 \mathrm{I}_{2}$. Canadian Journal of Chemistry. 1989;67(9):1416-1420.

[32] Cristiani F, Devillanova FA, Isaia F, Lippolis V, Verani G, Demartin F. Charge transfer complexes of benzoxazole-2 $(3 H)$ thione and benzoxazole-2(3H)-selone with diiodine: X-ray crystal structure of benzoxazole-2 $(3 H)$-thione bis(diiodine). Polyhedron. 1995;14(20-21):2937-2943.

[33] Bigoli F, Deplano P, Ienco A, et al. Structure and bonding of diiodine adducts of the sulfur-rich donors 1,3-dithiacyclohexane-2-thione (ptc) and 4,5-ethylenedithio-1,3-dithiole-2-thione (ttb). Inorganic Chemistry. 1999;38(21):46264636.

[34] Bigoli F, Deplano P, Mercuri ML, et al. Evaluation of thermodynamic parameters for highly correlated chemical systems: a spectrophotometric study of the 1:1 and 2:1 equilibria between $I_{2}$ and $1,1^{\prime}$-methylenebis(3-methyl4-imidazoline-2-thione) (mbit) and 1, 1'-ethylenebis(3methyl-4-imidazoline-2-thione) (ebit). Crystal and molecular structures of mbit $\cdot 2 \mathrm{I}_{2}$ and ebit $\cdot 2 \mathrm{I}_{2}$. Journal of the Chemical Society, Dalton Transactions. 1996;(17):3583-3589.

[35] Yamamoto M, Wu LP, Kuroda-Sowa T, Maekawa M, Suenaga $Y$, Munakata $M$. Preparation, characterization and $\mathrm{X}$-ray crystal structures of $\mathrm{I}_{2}$ and copper(II) complexes of 2,11-dithia[3.3] paracyclophane. Inorganica Chimica Acta. 1997;258(1):87-91.

[36] Allshouse J, Haltiwanger RC, Allured V, Rakowski DuBois M. Molecular and polymeric compounds resulting from Lewis acid interactions with $[\mathrm{CpMo}(\mu-\mathrm{S}) \mathrm{N}-t-\mathrm{Bu}]_{2}$. Inorganic Chemistry. 1994;33(12):2505-2506.

[37] Bois D'Enghien-Peteau M, Meunier-Piret J, Van Meerssche M. Structure du complexe mérecyanine-iodide $2\left[\mathrm{C}_{9} \mathrm{H}_{11} \mathrm{~S}_{4} \mathrm{~N}_{3} \mathrm{O}\right] \cdot \mathrm{I}_{2}$. Journal de Chimie Physique et de Physico-Chimie Biologique. 1968;65:1221-1225.

[38] Bransford JM, Meyers EA. Bis(triphenylphosphinesulfideS-iodine, $\mathrm{C}_{36} \mathrm{H}_{30} \mathrm{I}_{6} \mathrm{P}_{2} \mathrm{~S}_{2}$. Crystal Structure Communications. 1978;7:697-702.

[39] Apperley DC, Bricklebank N, Hursthouse MB, Light ME, Coles SJ. Vibrational, 31P NMR and crystallographic studies of diiodine adducts of some bidentate tertiary phosphine sulfides. Polyhedron. 2001;20(15-16):1907-1913. 
[40] Allen DW, Berridge R, Bricklebank N, et al. Structural and magnetic properties of a novel ferrocenyl-diiodine charge transfer complex. Inorganic Chemistry. 2003;42(13):39753977.

[41] Bock H, Rauschenbach A, Näther C, Kleine M, Havlas Z. Interactions in crystals, 111 -crystallization and structure determination of donor/acceptor complexes between 1,2,4,5tetrakis(alkylthio)benzene derivatives and bromine or iodine. Liebigs Annales. 1996;(12):2185-2194.

[42] Boyle PD, Christie J, Dyer T, et al. Further structural motifs from the reactions of thioamides with diiodine and the interhalogens iodine monobromide and iodine monochloride: an FT-Raman and crystallographic study. Journal of the Chemical Society, Dalton Transactions. 2000;(18):3106-3112.

[43] Corban GJ, Hadjikakou SK, Hadjiliadis N, et al. Synthesis, structural characterization, and computational studies of novel diiodine adducts with the heterocyclic thioamides $N$ methylbenzothiazole-2-thione and benzimidazole-2-thione: implications with the mechanism of action of antithyroid drugs. Inorganic Chemistry. 2005;44(23):8617-8627.

[44] Antoniadis CD, Corban GJ, Hadjikakou SK, et al. Synthesis and characterization of $(\mathrm{PTU}) \mathrm{I}_{2} \quad(\mathrm{PTU}=6-n-$ propyl-2-thiouracil) and (CMBZT) $\mathrm{I}_{2}(\mathrm{CMBZT}=5$-chloro2-mercaptobenzothiazole) and possible implications for the mechanism of action of anti-thyroid drugs. European Journal of Inorganic Chemistry. 2003;(8):1635-1640.

[45] Daga V, Hadjikakou SK, Hadjiliadis N, Kubicki M, dos Santos JHZ, Butler IS. Synthesis, spectroscopic and structural characterization of novel diiodine adducts with the heterocyclic thioamides, thiazolidine-2-thione (tzdtH), benzothiazole-2thione (bztzdtH) and benzimidazole-2-thione (bzimtH). European Journal of Inorganic Chemistry. 2002;(7):1718-1728.

[46] Arca M, Demartin F, Devillanova FA, et al. Synthesis, X-ray crystal structure and spectroscopic characterization of the new dithiolene $\left[\mathrm{Pd}\left(\mathrm{Et}_{2} \mathrm{timdt}\right)_{2}\right]$ and of its adduct with molecular diiodine $\left[\mathrm{Pd}\left(\mathrm{Et}_{2} \mathrm{timdt}_{2}\right] \cdot \mathrm{I}_{2}\right.$. $\mathrm{CHCl}_{3}\left(\mathrm{Et}_{2} \mathrm{timdt}=\right.$ monoanion of 1,3-diethylimidazolidine2,4,5-trithione). Journal of the Chemical Society, Dalton Transactions. 1998;(22):3731-3736.

[47] Hartl H, Steidl S. Crystal molecular structure of tetrapyridine-di-(diiodothiocyanato)-cobalt(II), $\left[\mathrm{Co}(\mathrm{py})_{4}\left(\mathrm{NCS} \cdot \mathrm{I}_{2}\right)_{2}\right]$. Zeitschrift für Naturforschung B. 1976;32:6-10.

[48] Arca M, Demartin F, Devillanova FA, et al. A new assembly of diiodine molecules at the triphenylphosphine sulfide template. Journal of the Chemical Society, Dalton Transactions. 1999;(17):3069-3073.

[49] Apperley DC, Bricklebank N, Burns SL, Hibbs DE, Hursthouse MB, Malik KMA. Crystal structure of triphenylphosphine sulfide diiodine; the first crystallographically characterised 1:1 molecular charge-transfer complex of a tertiary phosphine sulfide with diiodine. Journal of the Chemical Society, Dalton Transactions. 1998;(8):1289-1292.

[50] Kuhn N, Bohnen H, Henkel G. On the reaction of carbine adducts of carbon disulfide with bromine and iodine. Zeitschrift für Naturforschung B. 1994;49:1473-1480.

[51] Lyon EJ, Musie G, Reibenspies JH, Darensbourg MY. Sulfur site iodine adduct of a nickel thiolate complex. Inorganic Chemistry. 1998;37(26):6942-6946.

[52] Ito S, Liang H, Yoshifuji M. Preparation, structure, and some coordination properties of 2-chloro-3,3-diphenyl-3thioxo-1-(2,4,6-tri-t-butylphenyl)-1,3-diphosphapropene. Chemical Communications. 2003;(3):398-399.

[53] Bigoli F, Deplano P, Mercuri ML, Pellinghelli MA, Trogu EF. Spectrophotometric study, crystal and molecular structure of the 1:1 complex between 1,3-dithiolane-2-thione and diiodine. Phosphorus, Sulfur and Silicon and the Related Elements. 1992;70(1-2):175-182.

[54] Bigoli F, Deplano P, Devillanova FA, et al. Syntheses, Xray crystal structures, and spectroscopic properties of new nickel dithiolenes and related compounds. Inorganic Chemistry. 1997;36(6):1218-1226.

[55] Bigoli F, Deplano P, Mercuri ML, Pellinghelli MA, Trogu EF. Synthetic, structural and spectroscopic studies of the donating properties of sulphur-rich molecules towards $\mathrm{I}_{2}$ :X-ray structure of 1,3-dithiole-2-thione diiodine. Phosphorus, Sulfur, Silicon and the Related Elements. 1992;72(1-4):65-72.

[56] Aragoni MC, Arca M, Demartin F, et al. A theoretical investigation of the donor ability of $\left[M\left(R, R^{\prime}\right.\right.$ timdt $\left.) 2\right]$ dithiolene complexes towards molecular diiodine $(\mathrm{M}=\mathrm{Ni}$, $\mathrm{Pd}, \mathrm{Pt} ; \mathrm{R}, \mathrm{R}$ 'timdt = formally monoreduced disubstituted imidazolidine-2,4,5- trithione). European Journal of Inorganic Chemistry. 2004;(15):3099-3109.

[57] Aragoni MC, Arca M, Demartin F, et al. Charge-Transfer adducts of $\mathrm{N}$-methylthiazolidine-2-thione with $\mathrm{IBr}$ and $\mathrm{I}_{2}$ : an example of polymorphism featuring interpenetrating $3 \mathrm{D}$ sub-component assemblies and halogen $\cdots \pi \cdots$ halogen weak interactions. submitted to Crystal Growth and Design.

[58] Cross WI, Godfrey SM, Jackson SL, McAuliffe CA, Pritchard RG. The reaction of the tertiary phosphine sulfides $\mathrm{R}_{3} \mathrm{PS}\left(\mathrm{R}=\mathrm{Ph}, \mathrm{Me}_{2} \mathrm{~N}\right.$ or $\left.\mathrm{C}_{6} \mathrm{H}_{11}\right)$ with $\mathrm{X}_{2}\left(\mathrm{X}_{2}=\right.$ $\mathrm{I}_{2}, \mathrm{Br}_{2}, \mathrm{IBr}$ or ICl); structural characterisation of the CT complexes $\left(\mathrm{Me}_{2} \mathrm{~N}\right)_{3} \mathrm{PSI}_{2}$ and $\mathrm{Ph}_{3} \mathrm{PS}\left(\mathrm{I}_{0.89} \mathrm{Br}_{0.11}\right) \mathrm{Br}$ and the ionic compound $\left[\left\{\left(\mathrm{Me}_{2} \mathrm{~N}\right)_{3} \mathrm{PS}\right\}_{2} S\right]^{2+} 2\left[\mathrm{Br}_{3}\right]^{-}$. Journal of the Chemical Society, Dalton Transactions. 1999;(13):2225-2230.

[59] Bricklebank N, Skabara PJ, Hibbs DE, Hursthouse MB, Malik KMA. Reaction of thiones with dihalogens; comparison of the solid state structures of 4,5-bis(methylsulfanyl)-1,3dithiole-2-thione-diiodine, -dibromine and -iodine monobromide. Journal of the Chemical Society, Dalton Transactions. 1999;(17):3007-3014.

[60] Lee L, Crouch DJ, Wright SP, et al. Supramolecular polymers of 4,5-bis (bromomethyl)-1,3-dithiole-2- thionedihalogen adducts. CrystEngComm. 2004;6:612-617.

[61] Skabara PJ, Berridge R, Bricklebank N, Lath H, Coles SJ, Horton PN. Self-assembly of halogen adducts of ester and carboxylic acid functionalised 1,3-dithiole-2-thiones. Polyhedron. 2006;25(4):989-995.

[62] Skabara PJ, Bricklebank N, Berridge R, et al. Crystal engineering towards highly ordered polymeric structures of 1,3dithiole-2-thione-dihalogen adducts. Journal of the Chemical Society, Dalton Transactions. 2000;(19):3235-3236.

[63] Blake AJ, Devillanova FA, Garau A, et al. Structural and spectroscopic studies of charge-transfer adducts formed between $\mathrm{IBr}$ and thioether crowns. Journal of the Chemical Society, Dalton Transactions. 1999;(4):525-532.

[64] McCullough JD, Knobler C, Baker C, Hope H. The crystal and molecular structure of the iodine monobromide complex of 1,4-dithiane, $\mathrm{C}_{4} \mathrm{H}_{8} \mathrm{~S}_{2} \cdot 2 \mathrm{IBr}$. Inorganic Chemistry. 1971;10(4):697-700.

[65] Aragoni MC, Arca M, Demartin F, et al. C.T. complexes and related compounds between $\mathrm{S}$ and Se containing donors and $\mathrm{I}_{2}, \mathrm{Br}_{2}, \mathrm{IBr}$ ICl. Trends in Inorganic Chemistry. 1999;6:1-18.

[66] Aragoni MC, Arca M, Demartin F, et al. DFT calculations, structural and spectroscopic studies on the products formed between $\mathrm{IBr}$ and $N, N^{\prime}$-dimethylbenzoimidazole2(3H)-thione and $-2(3 H)$-selone. Dalton Transactions. 2005; (13):2252-2258. 
[67] Arca M, Devillanova FA, Garau A, et al. 31P CP-MAS NMR, vibrational, and X-ray characterization of the adducts of triphenylphosphine sulfide with ICl and IBr. Zeitschrift für anorganische und allgemeine Chemie. 1998;624(4):745-749.

[68] Demartin F, Devillanova FA, Garau A, Isaia F, Lippolis V, Verani G. Reactions of $\mathrm{N}$-methylbenzothiazole-2 $(3 H)$-thione (1) and -selone (2) with ICl: synthesis and X-ray crystal structures of the charge-transfer adducts $1 \cdot$ ICI (I) and $2 \cdot$ ICI (II). Polyhedron. 1999;18(24):3107-3113.

[69] Godfrey SM, McAuliffe CA, Pritchard RG, Sarwar S. Crystallographic characterisation of dihalogenodimethylselenium compounds, $\mathrm{Me}_{2} \mathrm{SeX}_{2}(\mathrm{X}=\mathrm{CI}, \mathrm{Br}$ or I) and the dependence of their structures on the nature of the halogen. Journal of the Chemical Society, Dalton Transactions. 1997;(6):1031-1035.

[70] Godfrey SM, Jackson SL, McAuliffe CA, Pritchard RG. Reaction of $\mathrm{R}_{3} \mathrm{PSe}$ with $\mathrm{I}_{2}$; crystal structures of $\mathrm{Ph}_{3} \mathrm{PSeI}_{2}$, $\left(\mathrm{Me}_{2} \mathrm{~N}\right)_{3} \mathrm{PSeI}_{2}$ and $\left(\mathrm{Et}_{2} \mathrm{~N}\right)_{3} \mathrm{PSeI}_{2}$, the first crystallographically characterised charge-transfer complexes of tertiary phosphine selenides with diiodine. Journal of the Chemical Society, Dalton Transactions. 1997;(23):4499-4502.

[71] Bigoli F, Deplano P, Devillanova FA, et al. Reaction of imidazole-2-selone derivatives with diiodine: synthesis, structural and spectroscopic characterization of the adduct 1,1'-bis(3-methyl-4-imidazolin-2-selone)methane bis(diiodine) and of the first examples of I-Se-I hypervalent selenium-compounds - 1,3-dimethyl-4-imidazolin-2-ylium diiodo selenanide and 1,2-bis(3-methyl-4-imidazolin-2ylium diiodo selenanide)-ethane bis(dichloromethane). Gazzetta Chimica Italiana. 1994;124(11):445-454.

[72] Demartin F, Devillanova FA, Isaia F, Lippolis V, Verani G. Reaction of $N, N^{\prime}$-dimethylimidazolidine-2-selone (L) with $\mathrm{I}_{2} \cdot$ crystal structure of the mixed-valence $\left(\mathrm{L} \cdot \mathrm{I}_{2}\right)\left(\mathrm{L}_{2}\right)^{2+} \cdot 2 \mathrm{I}_{3}^{-}$compound. Inorganica Chimica Acta. 1997;255(1):203-205.

[73] Hope H, McCullough JD. The crystal structure of the molecular complex of iodine with tetrahydroselenophene, $\mathrm{C}_{4} \mathrm{H}_{8} \mathrm{Se}$. $\mathrm{I}_{2}$. Acta Crystallographica. 1964;17(6):712-718.

[74] Chao GY, McCullough JD. The refinement of the structure of the complex of iodine with 1,4-diselenane, $\mathrm{C}_{4} \mathrm{H}_{8} \mathrm{Se}_{2} \cdot 2 \mathrm{I}_{2}$. Acta Crystallographica. 1961;14(9):940-945.

[75] Maddox H, McCullough JD. The crystal and molecular structure of the iodine complex of 1-Oxa-4-selenacyclohexane, $\mathrm{C}_{4} \mathrm{H}_{8} \mathrm{OSe} \cdot \mathrm{I}_{2}$. Inorganic Chemistry. 1966;5(4):522-526.

[76] Kubiniok S, du Mont W-W, Pohl S, Saak W. The reagent diphenyldiselane/iodine: no phenylselenenyl iodide but a charge transfer complex with cyclic moieties. Angewandte Chemie International Edition in English. 1988;27(3):431-433.

[77] Rudd MD, Lindeman SV, Husebye S. Three-centre, fourelectron bonding and structural characteristics of twocoordinate iodine(I) complexes with halogen and chalcogen ligands. Synthesis, spectroscopic characterization and X-ray structural studies of (Triiodo)[tris(dimethylamino)phosphaneselenide]iodine(I) and Bis(triiodo)[tri( $N$-morpholyl)phosphaneselenide]-iodine(I)/diiodine molecular complex. Acta Chemica Scandinavica. 1997;51(6-7):689-708.

[78] du Mont W-W, Martens A, Pohl S, Saak W. Reversible dismutation and coordination of bis(2,4,6-triisopropylphenyl) diselenide with iodine. A model study that relates to iodine intercalation between selenium chains. Inorganic Chemistry. 1990;29(24):4847-4848.

[79] Jeske J, du Mont W-W, Jones PG. Iodophosphane selenides: building blocks for supramolecular soft-soft chain, helix, and base-pair arrays. Chemistry - A European Journal. 1999;5(1):385-389.
[80] Antoniadis CD, Blake AJ, Hadjikakou SK, et al. Structural characterization of selenium and selenium-diiodine analogues of the antithyroid drug 6-n-propyl-2-thiouracil and its alkyl derivatives. Acta Crystallographica Section B. 2006;62(4):580-591.

[81] Cristiani F, Demartin F, Devillanova FA, Isaia F, Lippolis V, Verani G. Charge-transfer complexes of $N$-methylthiazolidine-2(3H)-selone (1) and $N$-methylbenzothiazole-2 $(3 H)$ selone (2) with $\mathrm{I}_{2}$ and $\mathrm{IBr}$ : crystal structures of $1 \cdot \mathrm{I}_{2}$, $1 \cdot \mathrm{I}_{1.25} \mathrm{Br}_{0.75}, 2 \cdot 2 \mathrm{I}_{2}$ and $2 \cdot 2 \mathrm{IBr}$. Inorganic Chemistry. 1994;33(26):6315-6324.

[82] Godfrey SM, McAuliffe CA, Pritchard RG, Sarwar S. Structural characterisation of the diorganoselenium interhalogen compounds $\mathrm{R}_{2} \mathrm{SeIBr}(\mathrm{R}=\mathrm{Ph}$ or $\mathrm{Me})$ and the ionic compound $\left[\mathrm{Me}_{3} \mathrm{Se}\right]\left[\mathrm{IBr}_{2}\right]$. Journal of the Chemical Society, Dalton Transactions. 1997;(19):3501-3504.

[83] Boyle PD, Cross WI, Godfrey SM, McAuliffe CA, Pritchard $\mathrm{RG}$, Teat $\mathrm{S}$. The reaction of $N$-methylbenzothiazole-2-selone with the interhalogens iodine monobromide and iodine monochloride. Journal of the Chemical Society, Dalton Transactions. 1999;(13):2219-2223.

[84] Knobler C, McCullough JD. The crystal and molecular structure of the iodine monochloride complex of 1-oxa4-selenacyclohexane, $\mathrm{C}_{4} \mathrm{H}_{8} \mathrm{OSe} \cdot \mathrm{ICI}$. Inorganic Chemistry. 1968;7(2):365-369.

[85] Godfrey SM, Jackson SL, McAuliffe CA, Pritchard RG. Reaction of tertiary phosphine selenides, $\mathrm{R}_{3} \mathrm{PSe}\left(\mathrm{R}=\mathrm{Me}_{2} \mathrm{~N}, \mathrm{Et}_{2} \mathrm{~N}\right.$ or $\mathrm{C}_{6} \mathrm{H}_{11}$ ), with dibromine. The first reported examples of 1:1 addition. Journal of the Chemical Society, Dalton Transactions. 1998;(24):4201-4204.

[86] Boyle PD, Cross WI, Godfrey SM, McAuliffe CA, Pritchard RG, Teat SJ. Reaction of dimethylselenourea and selenourea with dibromine to produce selenourea-dibromine, the ' $\mathrm{T}$ '-shaped 1:1 molecular adduct $N, N$-dimethyl2-selenourea-dibromine, its solvent of crystallisationcontaining analogue and the unusual ionic compound $5\left[\left(\mathrm{H}_{2} \mathrm{~N}\right)\left(\mathrm{Me}_{2} \mathrm{~N}\right) \mathrm{CBr}\right]^{+}\left[\mathrm{SeBr}_{6}\right]^{2-}\left[\mathrm{Se}_{2} \mathrm{Br}_{9}\right]^{-} 2\left[\mathrm{Br}_{3}\right]^{-}$. $\quad \mathrm{A}$ low temperature crystallographic reinvestigation of $\mathrm{N}$ methylbenzothiazole-2-selone-dibromine. Journal of the Chemical Society, Dalton Transactions. 1999;(16):2845-2852.

[87] Boyle PD, Godfrey SM, Pritchard RG. The reaction of Nmethylbenzothiazole-2-selone and 1,1-dimethylselenourea with sulfuryl chloride and dichlorine. Journal of the Chemical Society, Dalton Transactions. 1999;(23):4245-4250.

[88] Aragoni MC, Arca M, Demartin F, et al. Mechanistic aspects of the reaction between $\mathrm{Br}_{2}$ and chalcogenone donors (LE; $\mathrm{E}=\mathrm{S}, \mathrm{Se}$ ): Competitive formation of 10-E-3, T-shaped 1:1 molecular adducts, charge-transfer adducts, and $\left[(\mathrm{LE})_{2}\right]^{2+}$ dications. Chemistry - A European Journal. 2001;7(14):31223133.

[89] Aragoni MC, Arca M, Blake AJ, et al. 1,2-Bis(3-methylimidazolin-2-ylium iodobromoselenanide)ethane: oxidative addition of $\mathrm{IBr}$ at the Se atom of a $>\mathrm{C}=$ Se group. Angewandte Chemie-International Edition. 2001;40(22):42294232.

[90] Demartin F, Deplano P, Devillanova FA, Isaia F, Lippolis V, Verani G. Conductivity, FT-Raman spectra, and Xray crystal structures of two novel $\left[\mathrm{D}_{2} \mathrm{I}\right] \mathrm{I}_{2} \quad(n=3$ and $\mathrm{D}=N$-methylbenzothiazole-2 $(3 H)$ - selone; $n=7$ and $\mathrm{D}=\mathrm{N}$-methylbenzothiazole-2(3H)-thione) iodonium salts. First example of $\mathrm{I}^{-} \cdot 3 \mathrm{I}_{2}$ heptaiodide. Inorganic Chemistry. 1993;32(17):3694-3699. 
[91] Bigoli F, Demartin F, Deplano P, et al. Synthesis, characterization, and crystal structures of new dications bearing the -Se-Se- bridge. Inorganic Chemistry. 1996;35(11):3194-3201.

[92] Aragoni MC, Arca M, Devillanova FA, et al. Squarepyramidal bonding of $\mathrm{I}_{2}$ molecules at the $\mathrm{I}^{-}$nodes of a polyiodide infinite pseudo-cubic 3D-network. CrystEngComm. 2004;6:540-542.

[93] Aragoni MC, Arca M, Devillanova FA, et al. Kinetic and thermodynamic aspects of the CT and T-shaped adduct formation between 1,3-dimethylimidazoline-2-thione (or -2selone) and halogens. European Journal of Inorganic Chemistry. 2006;(11):2166-2174.

[94] Vaughan GBM, Mora AJ, Fitch AN, Gates PN, Muir AS. A high resolution powder X-ray diffraction study of the products of reaction of dimethyl sulfide with bromine; crystal and molecular structures of $\left(\mathrm{CH}_{3}\right)_{2} \mathrm{SBr}_{n}(n=2,2.5$ or 4). Journal of the Chemical Society, Dalton Transactions. 1999;(1):79-84.

[95] Wells AF. Structural Inorganic Chemistry. 5th ed. Oxford, UK: Clarendon Press; 1984.

[96] van Bolhuis F, Koster PB, Migchelsen T. Refinement of the crystal structure of iodine at $110^{\circ} \mathrm{K}$. Acta Crystallographica. 1967;23(1):90-91.

[97] Deplano P, Devillanova FA, Ferraro JR, Isaia F, Lippolis V, Mercuri ML. On the use of Raman spectroscopy in the characterization of iodine in charge-transfer complexes. Applied Spectroscopy. 1992;46(11):1625-1629.

[98] Swink LN, Carpenter GB. The crystal structure of iodine monobromide, IBr. Acta Crystallographica Section B. 1968;24(3):429-433.

[99] Bernardinelli G, Gerdil R. 2-chloroquinoline iodomonochloride. Acta Crystallographica Section B. 1976;32(6):1906-1907.

[100] Bricklebank N, Godfrey SM, Lane HP, McAuliffe CA, Pritchard RG, Moreno JM. Synthesis and structural characterisation of $\mathrm{R}_{3} \mathrm{AsX} \mathrm{X}_{2}$ compounds $\left(\mathrm{R}=\mathrm{Me}, \mathrm{Ph}, p-\mathrm{FC}_{6} \mathrm{H}_{4}\right.$ or $p$ - $\mathrm{MeOC}_{6} \mathrm{H}_{4} ; \mathrm{X}_{2}=\mathrm{Br}_{2}, \mathrm{I}_{2}$ or IBr); dependency of structure on $\mathrm{R}, \mathrm{X}$ and the solvent of preparation. Journal of the Chemical Society, Dalton Transactions. 1995;(23):3873-3879.

[101] Hrib CG, Ruthe F, Seppälä E, et al. The bromination of bulky trialkylphosphane selenides $\mathrm{R}_{2} \mathrm{R}^{\prime}$ PSe $\left(\mathrm{R}, \mathrm{R}^{\prime}=i \operatorname{Pr}\right.$ or $\left.t \mathrm{Bu}\right)$ studied by physical and computational methods. European Journal of Inorganic Chemistry. 2006;(1):88-100.

[102] Abbas S, Godfrey SM, McAuliffe CA, Pritchard RG. A cubic modification of (triphenylarsine)diiodine. Acta Crystallographica Section C. 1994;50(5):717-719.

[103] Godfrey SM, McAuliffe CA, Mushtaq I, Pritchard RG, Sheffield JM. The structure of $\mathrm{R}_{3} \mathrm{PBr}_{2}$ compounds in the solid state and in solution; geometrical dependence on $\mathrm{R}$, the crystal structures of tetrahedral ionic $\mathrm{Et}_{3} \mathrm{PBr}_{2}$ and molecular trigonal bipyramidal $\left(\mathrm{C}_{6} \mathrm{~F}_{5}\right)_{3} \mathrm{PBr}_{2}$. Journal of the Chemical Society, Dalton Transactions. 1998;(22):3815-3818.

[104] Godfrey SM, McAuliffe CA, Pritchard RG, Sheffield JM, Thompson GM. Structure of $\mathrm{R}_{3} \mathrm{PCI}_{2}$ compounds in the solid state and in solution: dependency of structure on R. Crystal structures of trigonal bipyramidal $\left(\mathrm{C}_{6} \mathrm{~F}_{5}\right)_{3} \mathrm{PCI}_{2}$, $\mathrm{Ph}_{2}\left(\mathrm{C}_{6} \mathrm{~F}_{5}\right) \mathrm{PCI}_{2}$ and of ionic $\mathrm{Pr}_{3}^{\mathrm{n}} \mathrm{PCI}_{2}$. Journal of the Chemical Society, Dalton Transactions. 1997;(24):4823-4827.

[105] Svenson PH, Kloo L. Synthesis, structure, and bonding in polyiodide and metal iodide-iodine systems. Chemical Reviews. 2003;103(5):1649-1684.

[106] Blake AJ, Li W-S, Lippolis V, et al. Template selfassembly of polyiodide networks. Chemical Society Reviews. 1998;27(3):195-206.
[107] Aragoni MC, Arca M, Devillanova FA, et al. First example of an infinite polybromide 2D-network. Chemical Communications. 2003;(17):2226-2227.

[108] Horn CJ, Blake AJ, Champness NR, et al. Helical templating of polyiodide networks at a binuclear metallo complex. Chemical Communications. 2003;(3):312-313.

[109] Horn CJ, Blake AJ, Champness NR, Lippolis V, Schröder M. Construction of the first cross-linked double helical polyiodide. Chemical Communications. 2003;(13):1488-1489.

[110] Aragoni MC, Arca M, Demartin F, et al. $[\mathrm{Ni}(\mathrm{L})(\mathrm{MeCN})]^{2+}$ complex cation as a template for the assembly of extended $\mathrm{I}_{3}^{-}$. $\mathrm{I}_{5}^{-}$and $\mathrm{I}_{5}^{-} \cdot \mathrm{I}_{7}^{-}$polyiodide networks $\mathrm{L}=2,5$, 8-trithia[9] $(2,9)$ 1,10-phenanthrolinophane. Synthesis and structures of $[\mathrm{Ni}(\mathrm{L})(\mathrm{MeCN})] \mathrm{I}_{8}$ and $[\mathrm{Ni}(\mathrm{L})(\mathrm{MeCN})] \mathrm{I}_{12}$. Inorganica Chimica Acta. 2004;357(12):3803-3809.

[111] Deplano P, Devillanova FA, Ferraro JR, Mercuri ML, Lippolis V, Trogu EF. FT-Raman study on charge-transfer polyiodide complexes and comparison with resonance Raman results. Applied Spectroscopy. 1994;48(10):1236-1241.

[112] Deplano P, Ferraro JR, Mercuri ML, Trogu EF. Structural and Raman spectroscopic studies as complementary tools in elucidating the nature of the bonding in polyiodides and in donor- $\mathrm{I}_{2}$ adducts. Coordination Chemistry Reviews. 1999;188(1):71-95.

[113] Blake AJ, Gould RO, Li W-S, et al. Silver-thioether crown complexes as templates for the synthesis of extended polyiodide networks: synthesis and X-ray crystal structures of $\left[\operatorname{Ag}_{2}\left([15] \mathrm{aneS}_{5}\right)_{2}\right] \mathrm{I}_{12},\left[\mathrm{Ag}\left([18] \mathrm{aneS}_{6}\right)\right] \mathrm{I}_{7}$, $\left[\mathrm{Ag}\left([18] \mathrm{aneS}_{6}\right)\right] \mathrm{I}_{3}$, and $\left[\mathrm{Ag}\left([9] \mathrm{aneS}_{3}\right)_{2}\right] \mathrm{I}_{5}$. Inorganic Chemistry. 1998;37(20):5070-5077.

[114] Perkins CW, Martin JC, Arduengo AJ, Lau W, Alegria A, Kochi JK. An electrically neutral $\sigma$-sulfuranyl radical from the homolysis of a perester with neighboring sulfenyl sulfur: 9-S-3 species. Journal of the American Chemical Society. 1980;102(26):7753-7759.

[115] Khun N, Kratz T, Henkel G. Derivate des Imidazols, IX. Stabilisierung von Selendiiodid durch Komplexbildung. Chemische Berichte. 1994;127(5):849-851.

[116] Arduengo AJ, Burgess EM. Tricoordinate hypervalent sulfur compounds. Journal of the American Chemical Society. 1977;99(7):2376-2378.

[117] Bigoli F, Deplano P, Devillanova FA, et al. A spectroand conductometric study of the reaction of imidazoline2-selone derivatives with bromine-crystal structure of 1,2-Bis(3-methyl-4-imidazolin-2-ylium dibromoselenanide)ethane. European Journal of Inorganic Chemistry. 1998;1998(1):137-141.

[118] Mancini A. [PhD thesis]. Cagliari, Italy: University of Cagliari; 2006.

[119] Hrib CG, Jones PG, du Mont W-W, Lippolis V, Devillanova FA. Complexes of bidentate phosphane selenide ligands with mesitylenetellurenyl iodide and with tellurium diiodide. European Journal of Inorganic Chemistry. 2006;(6):1294-1302. 


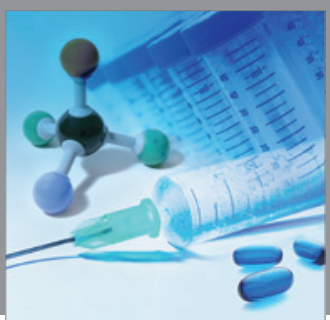

International Journal of

Medicinal Chemistry

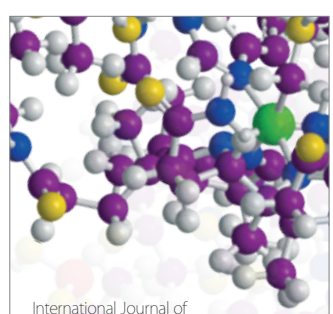

Carbohydrate Chemistry

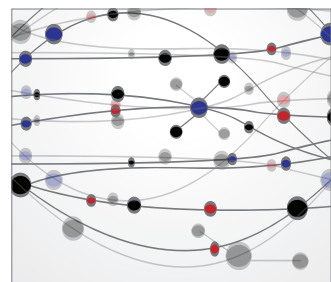

The Scientific World Journal
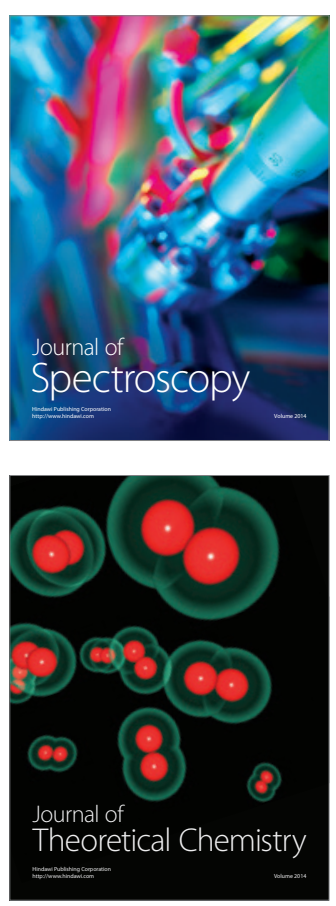
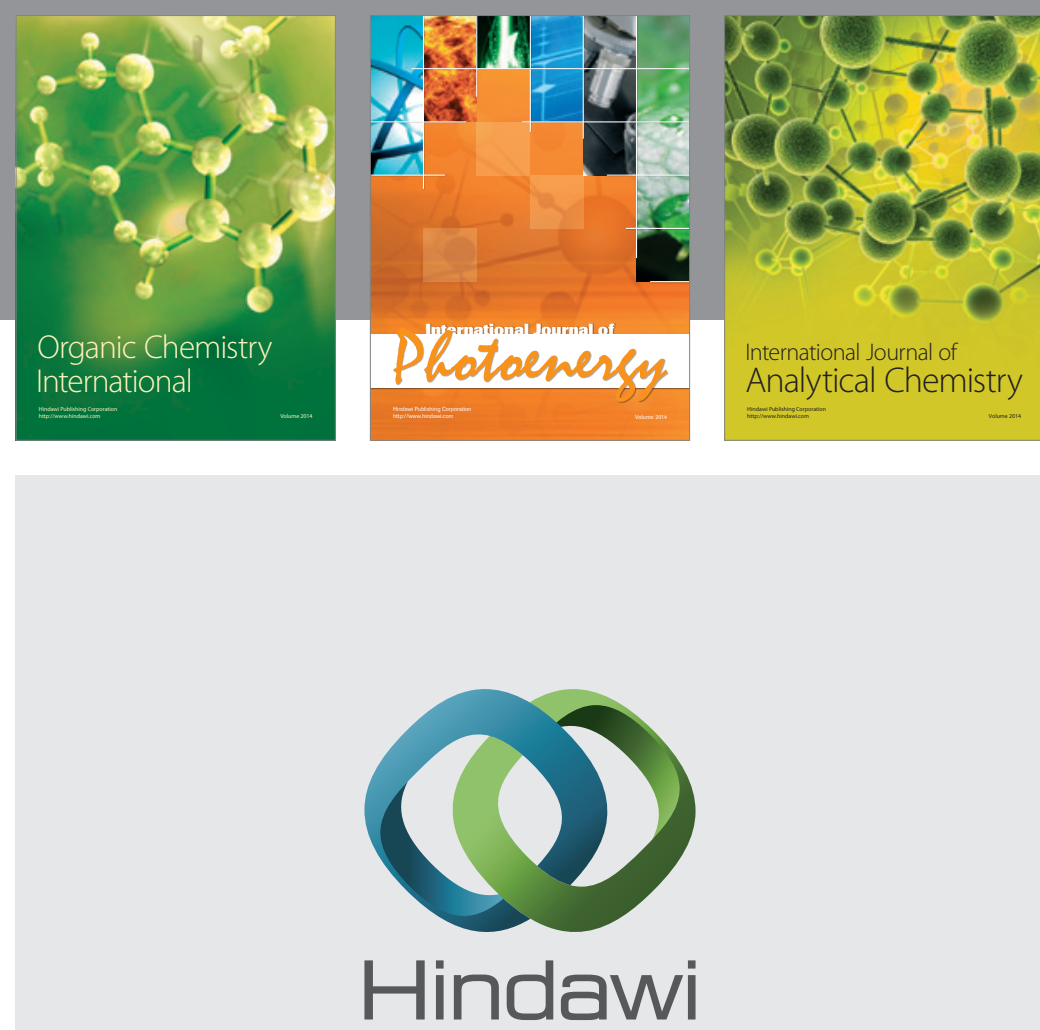

Submit your manuscripts at

http://www.hindawi.com
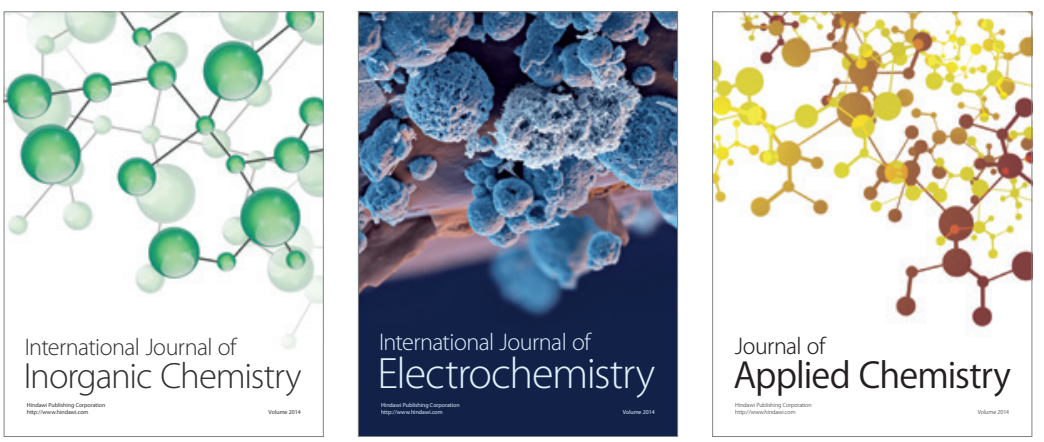

Journal of

Applied Chemistry
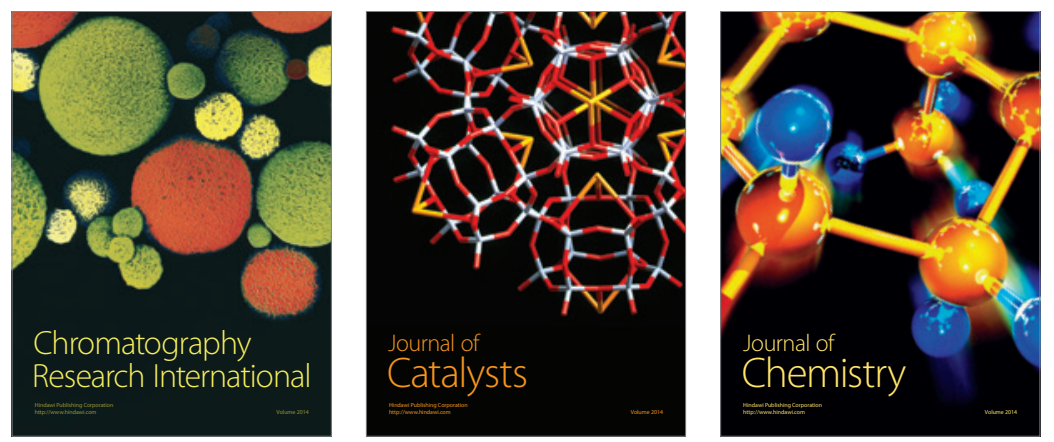
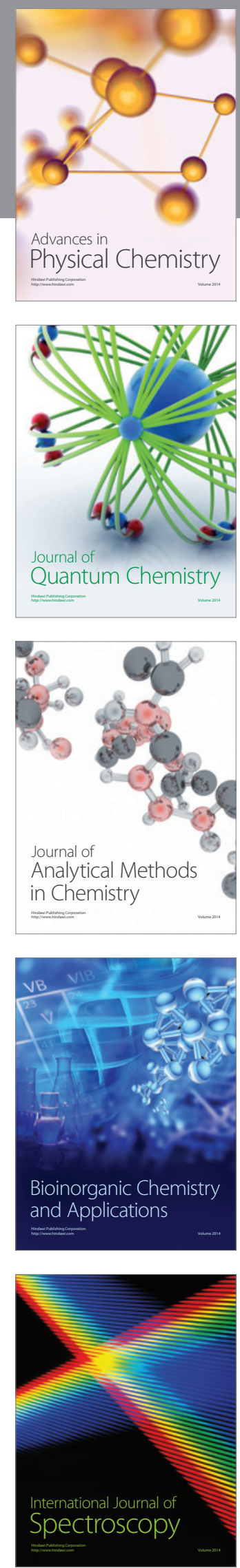